\title{
Hydraulics and Mixing of the Deep Overflow in the Lifamatola Passage of the Indonesian Seas
}

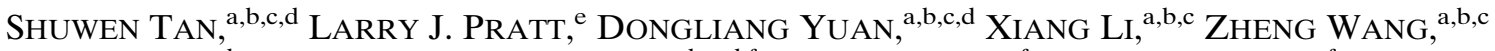 \\ YAO Li, ${ }^{a, b, c}$ CORRY CORVIANAWATIE,, a,b,c,d,f DEWI SURINATI, ${ }^{f}$ ASEP S. BUDIMAN, ${ }^{\mathrm{f}}$ AND \\ AHMAD BAYHAQI ${ }^{\mathrm{f}}$ \\ ${ }^{a}$ Key Laboratory of Ocean Circulation and Waves, Institute of Oceanology, Chinese Academy of Sciences, Qingdao, China \\ ${ }^{\mathrm{b}}$ Qingdao National Laboratory for Marine Science and Technology, Qingdao, China \\ ${ }^{\mathrm{c}}$ Center for Ocean Mega-Science, Chinese Academy of Sciences, Qingdao, China \\ ${ }^{\mathrm{d}}$ University of Chinese Academy of Sciences, Beijing, China \\ ${ }^{\mathrm{e}}$ Department of Physical Oceanography, Woods Hole Oceanographic Institution, Woods Hole, Massachusetts \\ ${ }^{\mathrm{f}}$ Research Center for Oceanography, Indonesian Institute of Sciences, Jakarta, Indonesia
}

(Manuscript received 24 December 2019, in final form 1 May 2020)

\begin{abstract}
Hydrographic measurements recently acquired along the thalweg of the Lifamatola Passage combined with historical moored velocity measurements immediately downstream of the sill are used to study the hydraulics, transport, mixing, and entrainment in the dense overflow. The observations suggest that the mean overflow is nearly critical at the mooring site, suggesting that a weir formula may be appropriate for estimating the overflow transport. Our assessment suggests that the weir formulas corresponding to a rectangular, triangular, or parabolic cross section all result in transports very close to the observation, suggesting their potential usage in long-term monitoring of the overflow transport or parameterizing the transport in numerical models. Analyses also suggest that deep signals within the overflow layer are blocked by the shear flow from propagating upstream, whereas the shallow wave modes of the full-depth continuously stratified flow are able to propagate upstream from the Banda Sea into the Maluku Sea. Strong mixing is found immediately downstream of the sill crest, with Thorpe-scale-based estimates of the mean dissipation rate within the overflow up to $1.1 \times 10^{-7} \mathrm{~W} \mathrm{~kg}^{-1}$ and the region-averaged diapycnal diffusivity within the downstream overflow in the range of $2.3 \times 10^{-3}$ to $10.1 \times 10^{-3} \mathrm{~m}^{2} \mathrm{~s}^{-1}$. Mixing in the Lifamatola Passage results in $0.6-1.2-\mathrm{Sv}\left(1 \mathrm{~Sv} \equiv 10^{6} \mathrm{~m}^{3} \mathrm{~s}^{-1}\right)$ entrainment transport added to the overflow, enhancing the deep-water renewal in the Banda Sea. A bulk diffusivity coefficient estimated in the deep Banda Sea yields $1.6 \times 10^{-3} \pm 5 \times 10^{-4} \mathrm{~m}^{2} \mathrm{~s}^{-1}$, with an associated downward turbulent heat flux of $9 \mathrm{~W} \mathrm{~m}^{-2}$.
\end{abstract}

\section{Introduction}

The Indonesian Throughflow (ITF) is a conduit for mass, heat, and freshwater transports from the Pacific to the Indian Ocean, playing an important role in regional and global climate (e.g., Schneider 1998; Wajsowicz and Schneider 2001; Gordon 2005; Pandey et al. 2007; Yuan et al. 2011, 2013). Most of the approximately $15 \mathrm{~Sv}$ of the throughflow is from the North Pacific Ocean (Gordon et al. 1999, 2003a, 2010; Gordon 2005; $\left.1 \mathrm{~Sv} \equiv 10^{6} \mathrm{~m}^{3} \mathrm{~s}^{-1}\right)$ and is concentrated in the western reaches of the Indonesian Archipelago, especially in the Makassar Strait $(\sim 11.6 \mathrm{~Sv}$ from Gordon et al. 2010). Waters of South Pacific origin, however, enter the Indonesian Seas via the eastern route

\footnotetext{
Corresponding author: Dongliang Yuan, dyuan@qdio.ac.cn
}

(Fig. 1a), i.e., through the Maluku Sea into the Lifamatola Passage $(\sim 2000 \mathrm{~m})$ or through the Halmahera Sea (blocked below $550 \mathrm{~m}$ ) into the internal Banda Sea ( $\mathrm{Li}$ et al. 2020). Lower thermocline Antarctic Intermediate Waters and deeper Circumpolar Deep Waters are observed to enter the Banda Sea through the Lifamatola Passage (Talley and Sprintall 2005), mix with upper waters of the ITF, and eventually exit into the Indian Ocean via the Timor and Ombai Passages (Gordon et al. 2003b).

Temperature profiles collected during a cruise in 1985 suggest the presence of a dense overflow within $\sim 500 \mathrm{~m}$ above the sill of Lifamatola Passage $\left(1^{\circ} 47^{\prime} \mathrm{S}, 126^{\circ} 56^{\prime} \mathrm{E}\right)$. This flow first spills into the 5000-m-deep Seram Sea, and then into the 7000-m-deep Banda Sea across another 3500-m-deep sill (see Fig. 5 in van Aken et al. 1988). 


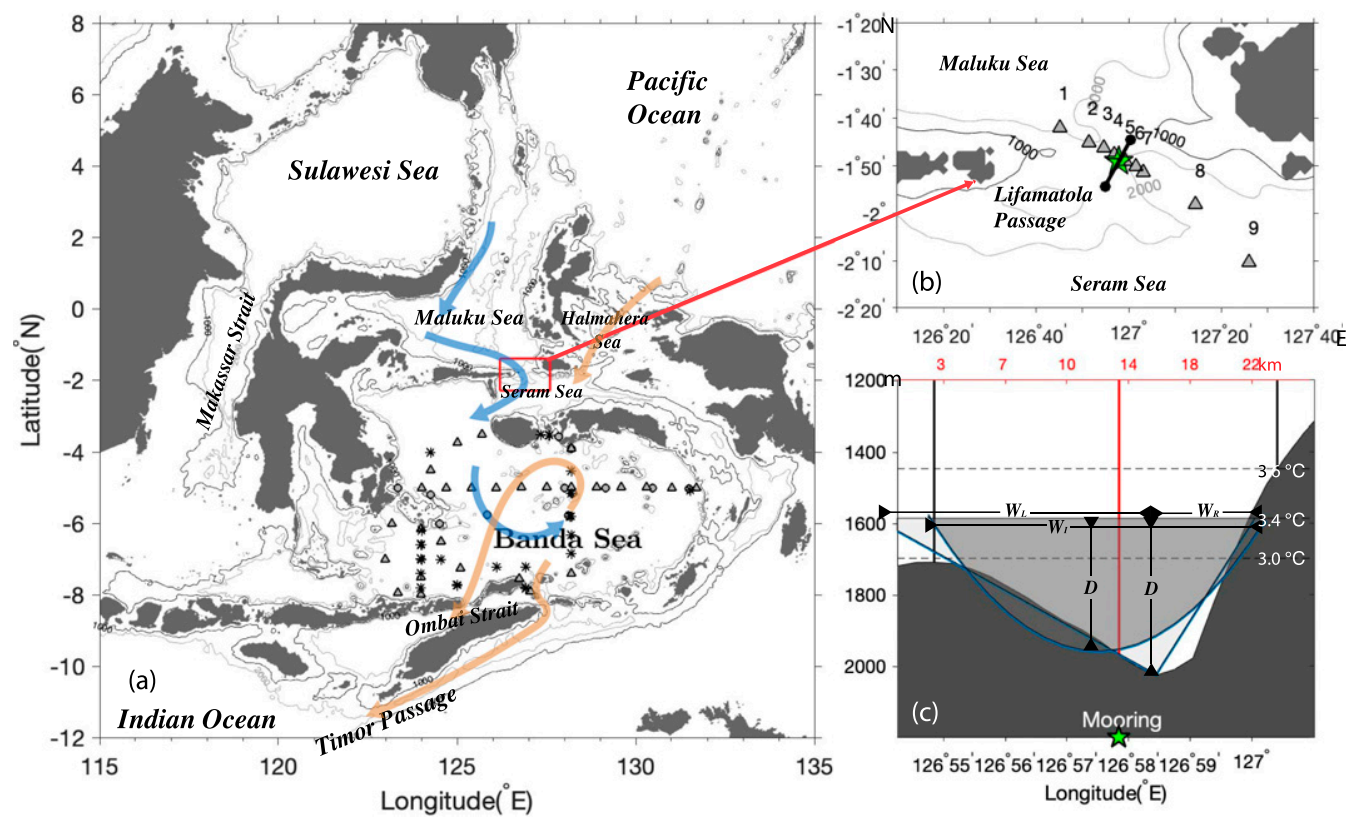

FIG. 1. (a) Map of the Indonesian Seas and schematic of the eastern route of the Indonesian Throughflow (ITF). The blue and yellow arrows show pathways of the deeper and shallower part of the ITF, respectively. Circles, triangles, and asterisks in the Banda Sea mark WOCE CTD stations that reach shallower than $2000 \mathrm{~m}$, 2000-3000 m, and deeper than $3000 \mathrm{~m}$, respectively. Black and gray contours [also in (b)] show the 1000- and 2000-m isobaths, respectively. (b) The boxed inset shows the map of the study region, CTD stations occupied from 29 to 30 Sep 2017 (numbered triangles), and the INSTANT mooring location (green star). The black line with dots on the ends represents the cross section used to estimate transport below $\Theta=3.6^{\circ} \mathrm{C}$ (c) The topography cross section at the mooring location (red line), with two black lines representing the location of the two ends [black dots in (b)] of the 21-km-wide section. The blue lines and curve are the best-fit triangle (light gray area) and parabola (dark gray area) to the topography below the $\Theta=3.4^{\circ} \mathrm{C}$ isotherm. The levels of $\Theta=3.0^{\circ}, 3.4^{\circ}$, and $3.6^{\circ} \mathrm{C}$ are shown in dashed lines.

The descending isotherms downstream of the sill crest along the thalweg of the Lifamatola Passage (van Aken et al. 1988; also see descending isotherms in Fig. 2) suggest hydraulic control, i.e., an asymmetry of flow characters (thickness, speed, etc.) across the sill. The asymmetric isotherms are typical of a subcritical-tosupercritical transition of a hydraulic flow, which implies blockage of certain types of internal waves from propagating upstream. So far, a quantitative evaluation of the flow hydraulics, which is important for understanding the communication of the Indian Ocean with the Pacific Ocean through the Lifamatola Passage, has not been conducted.

Downstream of a controlling sill, the supercritical flows are often subject to shear instability, breaking lee waves, and hydraulic jumps (e.g., Tessler et al. 2010; Alford et al. 2014; Cusack et al. 2019), resulting in substantial mixing and water mass modification (Bryden and Nurser 2003) accompanied by entrainment of overlying fluid with an increasing transport over distance. For example, the Denmark Strait overflow transport is almost doubled as a consequence of the entrainment dilution
(Girton and Sanford 2003). The overflow transport is estimated to be $2.5 \mathrm{~Sv}$ by van Aken et al. (2009) from a mooring deployed slightly downstream of the sill in the Lifamatola Passage. We may thus expect that the deep overflow eventually enters the Banda Sea with a larger transport than at the sill due to the entrainment. The downstream mixing and entrainment transport have not been quantified before.

To maintain a steady-state balance of volume and heat budgets in the deep Banda Sea, the deep overflow entering the Banda Sea must be lifted up through mixing to depths shallower than those of the sills of the exit straits of the Indonesian Seas. Direct mixing measurements and numerical modeling have suggested that mixing in the Indonesian Seas is highly variable, with enhanced tide-induced diapycnal mixing at sills and over continental shelves (Ffield and Gordon 1996; Hatayama 2004; Koch-Larrouy et al. 2007; Koch-Larrouy et al. 2015; Nagai et al. 2017). Microstructure observations of the central Banda Sea in the upper $300 \mathrm{~m}$ (Alford et al. 1999) and upper $1500 \mathrm{~m}$ (Koch-Larrouy et al. 2015), respectively, have shown very low mixing rates $\left(\sim 10^{-6} \mathrm{~m}^{2} \mathrm{~s}^{-1}\right)$. 


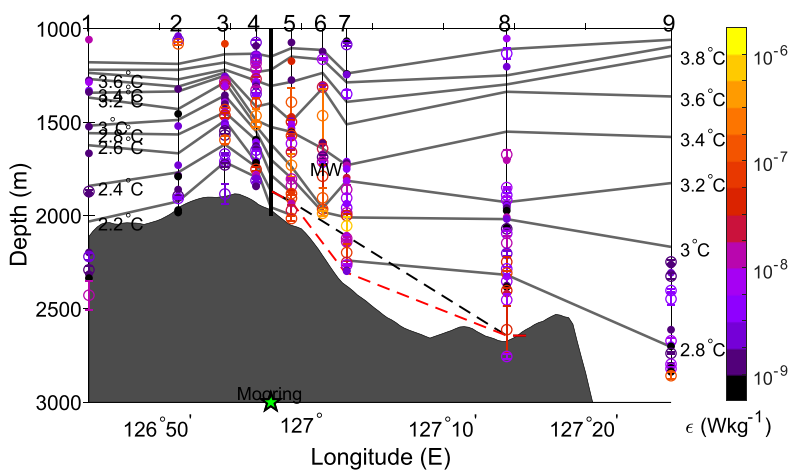

FIG. 2. Conservative Temperature $(\Theta)$ section along the thalweg of the Lifamatola Passage. Flow is to the right, and the locations of numbered CTD stations can be found in Fig. 1b. The vertical black thick line between CTD stations 4 and 5 indicates the location of the INSTANT mooring. Each colored vertical bar represents the vertical span of one identified overturn, and the same color circle (overturn larger than $10 \mathrm{~m}$ ) or dot (overturn smaller than $10 \mathrm{~m}$ ) marks the center location of the overturn. The colors correspond to the magnitude of the Thorpe-scale-based estimates of the turbulent dissipation rate $\varepsilon$. A mixed wedge (marked as MW) is bounded by the surfaces $\Theta=3.4^{\circ}$ and $3.2^{\circ} \mathrm{C}$, and the control volume below the $\Theta=3.4^{\circ} \mathrm{C}$ surface is employed to estimate the entrainment. Two estimates of the $\Theta=2.6^{\circ} \mathrm{C}$ isotherm are shown in black and red dashed lines.

In a basin-averaged view, the diapycnal diffusivity coefficient in the Banda Sea estimated from an advectiondiffusion model is on the order of $10^{-4}-10^{-3} \mathrm{~m}^{2} \mathrm{~s}^{-1}$ (van Aken et al. 1988; Ffield and Gordon, 1992; Hautala et al. 1996; van Aken et al. 2009). The spatial-averaged upwelling and mixing in the deep Banda Sea may be reevaluated by quantifying the volume and heat budgets of the basin, in which the fluxes of the entrainment downstream of the Lifamatola Passage are considered.

Since the hydrographic data of the historical cruises are not publicly available, this study will utilize a set of full-depth conductivity-temperature-depth (CTD) measurements recently collected along the axis of the overflow as well as 17 months of ADCP velocity data collected with a mooring deployed during 2005-06. This study will evaluate the hydraulics, mixing, and entrainment in the Lifamatola Passage. The CTD and mooring data are described in section 2 . In section 3 , the conditions for hydraulic control are assessed using the mooring data, and it is argued that the control is, in fact, present. Based on this finding, we predict volume fluxes from various "weir" formulas (i.e., estimating volume transport from stratification in different cross-section shapes) compared with fluxes estimated from the mooring measurements. In section 4, mixing and entrainment downstream of the sill are quantified, and we use the results to formulate a budget leading to estimates of the upwelling velocity and mixing rate within the Banda Sea. Discussion and conclusions appear in section 5 .

\section{Data}

A mooring has been deployed slightly downstream of the crest of the sill in the Lifamatola Passage as part of the International Nusantara Stratification and Transport (INSTANT) program twice: from January 2004 to July 2005, and from July 2005 to December 2006 (van Aken et al. 2009; dataset available on http:// www.marine.csiro.au/ cow074/instantdata.htm). The depth for the second mooring deployment was $2017 \mathrm{~m}$. The two RDI 75-kHz ADCPs with a measuring range of 500-600 $\mathrm{m}$ were mounted at depths of $\sim 800$ (looking upward) and $\sim 1400 \mathrm{~m}$ (looking downward), and data were recorded in 8-m bins. Two Aanderaa RCM 11 acoustic current meters were mounted between the ADCPs at an interval of about $300 \mathrm{~m}$. Temperatures and salinities were measured by three mounted Sea-Bird Electronics Microcats (SBE37SM) about every $300 \mathrm{~m}$ between $\sim 800$ and $\sim 1400 \mathrm{~m}$, and one additional SBE37SM was mounted at $10 \mathrm{~m}$ above the bottom. Considering that a substantial loss of ADCP coverage occurred in the first deployment and that the second deployment had a better SBE37SM coverage near the bottom, we will only employ measurements from the second deployments.

In consideration of data voids due to mooring blowdown during strong tides, van Aken et al. (2009) suggested that the throughflow of the Lifamatola Passage may be approximately treated as a superposition of a steady residual flow and tidal motions. The tidal motions were first estimated using a harmonic analysis (Pawlowicz et al. 2002) and then subtracted from the hourly velocity data to obtain a time series of the residual currents. We therefore filled the missing records with a summation of the mean of the residual currents and the tidal constitutes at fixed depth levels via linearly interpolating the raw data onto a 10-m grid between 300 and $2000 \mathrm{~m}$ (Fig. 3c). Similarly, hourly hydrographic profiles were constructed at depth levels every $50 \mathrm{~m}$ between 850 and $2000 \mathrm{~m}$ by filling the missing data with the tidal harmonics (Figs. 3a,b). The different grid spacings were determined considering that the bin size of ADCP measures was $8 \mathrm{~m}$ and the typical blowdown distance of an SBE37M was $30 \mathrm{~m}$ within a sampling interval.

A joint survey of the Indonesian Seas by the Institute of Oceanology of the Chinese Academy of Sciences and the Research Center for Oceanography of the Indonesian Institute of Sciences was conducted on board R/V BJ8 during 29-30 September 2017. Nine full-depth CTD casts were made along the thalweg of the passage (dataset available on http://itf.qdio.ac.cn/xzlxz/), with 


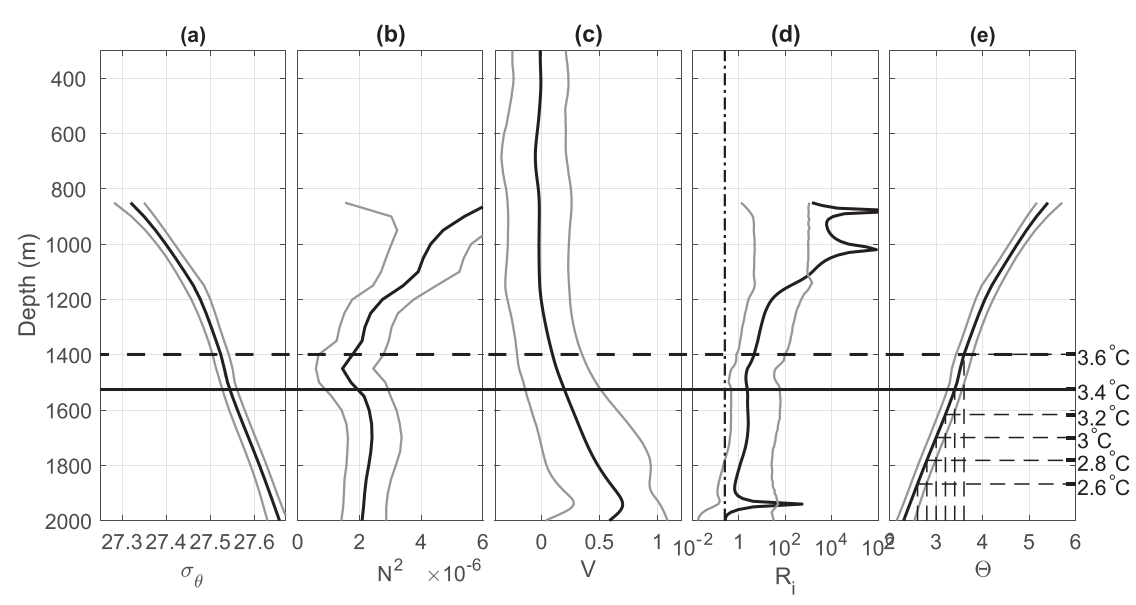

FIG. 3. (a) Potential density $\sigma_{\theta}\left(\mathrm{kg} \mathrm{m}^{-3}\right)$, (b) squared buoyancy frequency $N^{2}\left(\mathrm{~s}^{-2}\right)$, (c) mean velocity $V\left(\mathrm{~m} \mathrm{~s}^{-1}\right)$, (d) gradient Richardson number $R_{i}$, and (e) Conservative Temperature $\Theta\left({ }^{\circ} \mathrm{C}\right)$ from mooring measurements. Black thick profiles indicate time averages from mooring observations, and two gray thin profiles represent the 10th and 90th percentiles of variability, except for the black thick profile in (d) indicating $R_{i}$ estimated from the timemean $V$ and $N^{2}$. The dash-dotted line in (d) indicates $R_{i}=1 / 4$. The long horizontal black solid and dashed lines denote the depths of $\Theta=3.4^{\circ}$ and $3.6^{\circ} \mathrm{C}$, respectively.

the shortest horizontal spacing of about $4 \mathrm{~km}$ near the crest of the sill (Fig. 1b). The hydrographic profiles were measured using an SBE 911 plus CTD and gridded onto a 1-m grid. The accuracy and resolution of the CTD sensors are 0.002 and 0.001 psu for salinity and $0.001^{\circ}$ and $0.0002^{\circ} \mathrm{C}$ for temperature, respectively.

High-quality hydrographic measurements from CTD have also been collected as part of the international World Ocean Circulation Experiment (WOCE) Hydrographic Program in the 1990s in the Indonesian Seas (dataset available at http://cchdo.ucsd.edu; Gordon et al. 2003b). The historical dataset used in this study consists of an aggregate of 72 hydrographic profiles in the Banda Sea that have been measured by four cruises from the year 1993 to 1998, covering the upper ocean from the surface to 2000-3000 m (Fig. 1a).

\section{Transport and hydraulics in the Lifamatola Passage}

\section{a. Observed transport estimates}

The mean ADCP velocity profile combined with the high-resolution $\left(1^{\prime} \times 1^{\prime}\right)$ topography from ETOPO1 (dataset available on https://www.ngdc.noaa.gov/mgg/ global/; Amante and Eakins 2009), are used to estimate the Lifamatola Passage volume transports in the alongthalweg direction, which is aligned northwest to southeast at a compass angle of $150.5^{\circ}$ (Fig. 1b). Instead of characterizing the overflow and water mass by its potential density, we define the overflow in terms of Conservative
Temperature $(\Theta)$ since the density is mostly controlled by temperature in the deep Lifamatola Passage. Conservative Temperature $\Theta$, which is proportional to potential enthalpy $\left(h^{\circ}\right)$, obeys a simple conservation law (see appendix C) and leads to a precise measure of heat flux (McDougall 2003). Conservative Temperature $\Theta$ and $h^{\circ}$ are derived from the in situ temperature and salinity using the new equation of state of seawater TEOS-10 (McDougall and Barker 2011). The mean overflow transport is obtained from interpolating the mean velocities onto a $10-\mathrm{m}$ grid and integrating from the seafloor to a selected Conservative Temperature $(\Theta)$ surface.

The Conservative Temperature section along the thalweg of the Lifamatola Passage displayed in Fig. 2 is constructed from nine CTD casts made in 2017 and from the time-mean mooring measurements. The deep flow that spills down across the sill is largely confined to waters colder than $\Theta=3.6^{\circ} \mathrm{C}$. Moreover, of the surfaces that participate in the spilling, those in the range $3.0^{\circ}<$ $\Theta \leq 3.6^{\circ} \mathrm{C}$ tend to experience no further descent as they enter the Seram Sea, whereas surfaces with $\Theta \leq 3.0^{\circ} \mathrm{C}$ continue to descend, suggesting a possible role in ventilation of the deep basins downstream. In the following, we estimate mean volume transport for waters bounded above by the $\Theta=3.0^{\circ}$ and $3.6^{\circ} \mathrm{C}$ surfaces as well as several others.

Also required for transport estimates is information regarding the lateral (cross-passage) extent and the structure of the flow. The cross-section chosen to estimate the transport below $\Theta=3.6^{\circ} \mathrm{C}$ is indicated by the 
dark line in the inset map of Fig. 1b, with the solid dots at each end marking the lateral boundaries. The northeastern boundary $\left(1^{\circ} 44.21^{\prime} \mathrm{S}, 127^{\circ} 00.61^{\prime} \mathrm{E}\right)$ is chosen as the isobath that matches the elevation of the $\Theta=3.6^{\circ} \mathrm{C}$ surface at the mooring. Since to the southwest the topography shallows to a crest at about $1700-\mathrm{m}$ depth and then deepens further to the west (Fig. 1c), we define the topographic crest as the position of our western boundary, which places the boundary at a location $\left(1^{\circ} 54.40^{\prime} \mathrm{S}, 126^{\circ} 54.85^{\prime} \mathrm{E}\right)$ very close to that defined by van Aken et al. (2009). For transport below $\Theta=3.0^{\circ} \mathrm{C}$, the flow is confined by topography on either side and we define the boundaries accordingly. In their transport estimate of $2.5 \mathrm{~Sv}$ for flow below $1250 \mathrm{~m}$, van Aken et al. (2009) assumed that the velocity was laterally uniform. With the same assumption of lateral uniformity and with our edge definitions, our estimate of the transport below $\Theta=3.6^{\circ}, 3.4^{\circ}, 3.2^{\circ}$, and $3.0^{\circ} \mathrm{C}$ are $2.8,2.4,2.0$, and $1.5 \mathrm{~Sv}$, respectively. However, uncertainties exist due to assumptions of laterally uniform flow and of the location of the southwest boundary.

Flows in sea straits are often concentrated in a jet (e.g., Siddall et al. 2004) or a boundary current (Gill 1977). We rule out the possibility of the overflow being a boundary current since the local deformation radius $\sqrt{g^{\prime} D} /|f| \sim 124 \mathrm{~km}$ (where $g^{\prime} \sim 6.5 \times 10^{-4} \mathrm{~kg} \mathrm{~m}^{-3}$ is the reduced gravity, discussed further in section $3 \mathrm{~b}, D \sim$ $500 \mathrm{~m}$ is the typical layer thickness, and $f=-4.6 \times$ $10^{-6} \mathrm{~s}^{-1}$ is the Coriolis parameter) is much larger than the $\sim 21-\mathrm{km}$ width occupied by the deep layer. For a jetlike flow, assuming the mean velocity varies linearly from its maximum at the mooring site to zero at the edges, the transports are then exactly one-half of the values of the uniform flows: for example, $1.4 \mathrm{~Sv}$ below $\Theta=3.6^{\circ} \mathrm{C}$ and $0.75 \mathrm{~Sv}$ below $\Theta=3.0^{\circ} \mathrm{C}$.

\section{b. Hydraulic criticality}

The spilling and descent of dense fluid across the sill and into the Seram Sea suggests that the deep transport in the Lifamatola Passage may be hydraulically controlled, which implies some degrees of regulation of the overflow transport. Hydraulic control also suggests that the deep transport may be estimated based only on the topography and stratification instead of velocity. This could potentially be used as a parameterization in a model that is unable to resolve the topographic details of the Lifamatola Passage. It also suggests blocking of certain types of horizontally propagating waves that attempt to travel from the Seram Sea upstream into the Maluku Sea. In hydraulics, one is primarily interested in nondispersive long waves (wave lengths much greater than fluid depth) since these are most efficient at altering the upstream flow. Since we only have velocity measurements at the mooring location, we will evaluate the hydraulic state of flow there (slightly downstream of the sill crest) by calculating Froude numbers based on different simplifications of the mean flow.

By fitting the observed velocity and stratification to a 1.5-layer model configuration, one can make a crude estimate of the hydraulic state described by the common Froude number $F=V / \sqrt{g^{\prime} D}$, a ratio of the advection speed to the phase speed of long internal gravity waves. The 1.5-layer model assumes an active lower layer with uniform velocity $V$ and thickness $D$ and a quiescent upper layer, with a density jump represented by the reduced gravity $g^{\prime}$ at the interface. Earth's rotation is neglected due to the very large ratio of internal deformation radius to the channel width. The flow is hydraulically subcritical, critical, or supercritical according to $F<1, F=1$, or $F>1$, respectively. The transition of subcritical-to-supercritical overflow is expected to take place at the critical or control section, which generally coincides with the crest of the sill, and can be shifted elsewhere, usually downstream, as a result of bottom drag or entrainment (Pratt 1986; Gerdes et al. 2002).

The estimation of reduced gravity $g^{\prime}=g\left(\Delta \rho / \rho_{0}\right)$, which is proportional to the density jump $\Delta \rho$ across the interface, can be problematic. As shown in Figs. $3 a$ and $3 b$, no distinct density jump is evident in the time-average density profile, only a band of weakened stratification between $\Theta=3.4^{\circ}$ and $3.6^{\circ} \mathrm{C}$. If we choose the $\Theta=3.4^{\circ} \mathrm{C}$ surface as the interface, and estimate the upper-layer density as that averaged between $\Theta=3.4^{\circ}$ and $\Theta=3.6^{\circ} \mathrm{C}$, and the lower-layer density and velocity as the vertical average below $\Theta=3.4^{\circ} \mathrm{C}$, then $g^{\prime} \sim 6.5 \times 10^{-4} \mathrm{~kg} \mathrm{~m}^{-3}$. The estimated Froude number of the mean flow is about 0.8 , which would be lower had we chosen the upper-layer density to be a vertical average between $\Theta=3.4^{\circ} \mathrm{C}$ and the sea surface.

A more sophisticated version of the Froude number was derived by Nielsen et al. (2004), who accounted for the shear and density variations in the lower layer using "shape" coefficients $\alpha$ and $\beta$ (see appendix A for definitions). The resulting Froude number $F=(\alpha / \beta)^{1 / 2} V / \sqrt{g^{\prime} D}$ tends to be larger than the 1.5-layer estimate (Nielsen et al. 2004; Girton et al. 2006). For the present case, evaluation of this Froude number using the same value of $g^{\prime}$ as given above leads to a value of 1.1.

A third estimate, also based on an idealization of the flow, is to calculate the wave propagation speed of the first baroclinic mode for a flow with vertically uniform buoyancy frequency $N$ and velocity $V$ in the lower layer, and with quiescent and homogenous fluid above. This approach assumes that the weakly stratified layer between $\Theta=3.4^{\circ}$ and $3.6^{\circ} \mathrm{C}$ decouples the stratified 
underlying flow from shallower regions and avoids estimation of $g^{\prime}$. In the long-wave limit, the waves of the first baroclinic mode are analogous to waves in the 1.5-layer model. The propagation speed of the first mode is $c_{-1}=V-2 N D / \pi$, with the negative sign of the subscript representing upstream-propagating waves relative to the mean flow (see section 6.2 in Baines 1995). The corresponding Froude number yields $F_{1}=\pi V /(2 N D)$, which compares the flow speed with the phase speed of the first baroclinic mode for a quiescent fluid. Here we take the lower layer $N$ and $V$ as the vertical averages of the measured values below $\Theta=3.4^{\circ} \mathrm{C}$, we find a wave propagation speed of $-0.03 \mathrm{~m} \mathrm{~s}^{-1}$ (i.e., very slow upstream propagation) and $F_{1}=0.9$.

All three estimates are quite close to unity, suggesting that the flow is nearly critical at the mooring location. Although the lack of velocity measurements upstream and downstream prevents evaluation of the hydraulic states there, the near-criticality of the flow near the sill crest is consistent with the inspected subcritical-tosupercritical hydraulic transition from the descending feature of isotherms observed both in the hydrographic profiles from van Aken et al. (1988) and Fig. 2.

\section{c. Hydraulic transport estimates}

There are two types of transport (or "weir") formulas that relate the volume transport $Q$ to the observed stratification and topography. The first type requires knowledge of the stratification far upstream of the control section, and assumes the flow there is nearly quiescent, as in a large reservoir. Since our knowledge of the upstream conditions is limited, we employ a second class of formulas that depend only on the measured stratification at the mooring location, where the overflow is presumed to be critical. The results of the previous section suggest that this is approximately so. The transports for rectangular, triangular, and parabolic cross sections are given in the context of the 1.5-layer model described above (Pratt and Whitehead 2008; Chow 1959):

$$
\begin{aligned}
& Q=W g^{\prime 1 / 2} D^{3 / 2} \quad(\text { Rectangular) } \\
& Q=\frac{\gamma_{L}+\gamma_{R}}{2}\left(\frac{g^{\prime} D^{5}}{2}\right)^{1 / 2} \quad \text { (Triangular) } \\
& Q=2\left(\frac{2}{3}\right)^{3 / 2}\left(\frac{g^{\prime}}{\delta}\right)^{1 / 2} D^{2} \quad \text { (Parabolic) }
\end{aligned}
$$

For a rectangular cross section, $W$ and $D$ stand for the uniform channel width and layer thickness, respectively. For the other two cross sections, $D$ represents the layer thickness at the deepest point of the idealized geometry.
Parameters $\gamma_{L}$ and $\gamma_{R}$ are the slopes of the left-hand side and right-hand side walls (facing downstream) of the triangular cross section $\left(\gamma_{L}=W_{L} / D, \gamma_{R}=W_{R} / D\right.$, with $W_{L}$ and $W_{R}$ the widths of the flow interface to the left and right of the deepest point), and $\delta$ represents the curvature of the channel bottom at the sill for parabolic cross section $\left(\delta=4 D / W_{1}^{2}\right.$, where $W_{1}$ is the width of the interface).

Assuming that the overflow is critical at the mooring location and the flow interface coincides with the $\Theta=$ $3.4^{\circ} \mathrm{C}$ isotherm, one can determine the best fit $\gamma_{L}, \gamma_{R}, \delta$, and $D$ to the cross-section topography using a least squares fit (see the triangle and parabola in Fig. 1c). For the rectangular weir formula, $W$ and $D$ in (1) are determined by the mean channel width below the level of the interface $\int_{h}^{h+D} w(z) d z / D$, where $h$ is the bottom depth and the distance between the deepest depth and the interface, respectively. The rectangular, triangular, and parabolic weir formulas arrive at transports of 2.2,2.6, and $2.8 \mathrm{~Sv}$, respectively. We note that these hydraulic estimates of the volume flux are subject to uncertainty regarding flow criticality at the mooring station as well as uncertainty due to the estimate of $g^{\prime}$ and that the direct mooring measurements are also subject to a high degree of uncertainty due to the unknown spatial structure of the flow. In this regard, all three weir formulas estimates lie reasonably close to the mooring measurement of $2.4 \mathrm{~Sv}$, although the rectangular and triangular weir formulas give results that are closest to the observed value.

\section{d. Wave blockage and upstream propagation: Wave modes for continuously stratified shear flow}

A more general approach to assess the flow criticality, preferable where the flow lacks a clear layer interface, is to consider the wave modes of the continuously varying density and velocity profiles over the full water column, though this analysis does not easily lead to a weir formula. Here we summarize a computation of the wave modes at the mooring site, not only to assess the proximity of the flow at the mooring to hydraulic criticality but also to determine whether there are waves that are able to propagate upstream, from the Indian OceanBanda-Seram Sea regions, into the Maluku Sea and regions farther north.

We limit discussions to two-dimensional, infinitelylong waves since they tend to propagate more rapidly than waves with the same modal structure but finite wavelengths and are generally the key to upstream influence. The "upstream influence" refers to the ability of a sill or width contraction to regulate certain features of the flow far upstream and is generally communicated by long waves. These properties are 
discussed more fully in Pratt and Whitehead (2008) and Baines (1977, 1995).

The effects of Earth's rotation are ignored. The discrete vertical wave modes and corresponding propagation speeds are the eigenfunctions and eigenvalues of the Taylor-Goldstein (hereafter TG) equation:

$$
\left\{\begin{array}{c}
\hat{w}^{\prime \prime}+l^{2} \hat{w}=0, \\
l^{2}=\frac{N^{2}}{(V-c)^{2}}-\frac{V^{\prime \prime}}{V-c}-k^{2},
\end{array}\right.
$$

with $\hat{w}(0)=\hat{w}(D)=0$. Here $\hat{w}(z)$ gives the vertical structure of vertical velocity due to the wave, $c$ is the horizontal propagation speed of a vertical mode, $N^{2}(z)$ is the squared buoyancy frequency, $V(z)$ is the horizontal fluid velocity (positive in the direction of the Lifamatola outflow), $V^{\prime \prime}(z)$ represents the vorticity gradient due to the vertical shear, and the primes denote differentiation with respect to $z$. The vertical structure of the along-channel velocity of perturbation is given by $\hat{v}(z)=-(i / k) \hat{w}^{\prime}(z)$. For stationary $(c=0)$, long waves $(k=0), l^{2}$ is called the Scorer parameter (Scorer 1949). We will refer to $l^{2}$ with arbitrary $c$ and $k$ as the generalized Scorer parameter. Where the function $l^{2}$ is positive, the solutions for $\hat{w}$ oscillate in the $z$ direction. Sufficiently large $V^{\prime \prime}$ can cause $l^{2}$ to become negative, in which case the restoring mechanism associated with stratification has been vanquished by shear (Hogg et al. 2001). We use a code developed by Smyth et al. (2011) to solve (4), and we set $k=10^{-6} \mathrm{~m}^{-1}$ in all cases in order to approximate long waves since the nondispersive character of these waves is key to hydraulic control. The profile of the generalized Scorer parameter $l^{2}$ for each mode is calculated to assess the nature of wave modes given $k \sim 0$ and corresponding wave propagation speed $c$ (usually nonzero).

Mean profiles of $V$ and $N^{2}$ from the mooring measurements only cover ranges of $300-2000 \mathrm{~m}$ and 850 $2000 \mathrm{~m}$, respectively. In order to compute wave modes for the full-depth profiles, we extend the velocity profile above $300 \mathrm{~m}$ by filling data voids with zeros and construct a full-depth $N^{2}$ profile by linearly interpolating the potential density profiles between CTD stations 4 and 5 , which lie immediately upstream and downstream of the mooring. The potential density profile is then processed with a fourth-order Butterworth low-pass filter with a cutoff distance of $50 \mathrm{~m}$ to eliminate small-scale inversions due to intermittent overturns. The profile of $N^{2}$ is computed from the smoothed density profile and linearly interpolated onto a 10-m grid. The constructed $V$ and $N^{2}$ profiles ranging over $0-2000 \mathrm{~m}$ (Fig. 4a) are then used to solve the TG equations. Although the true bottom depth is $2007 \mathrm{~m}$, we treat the deepest data point
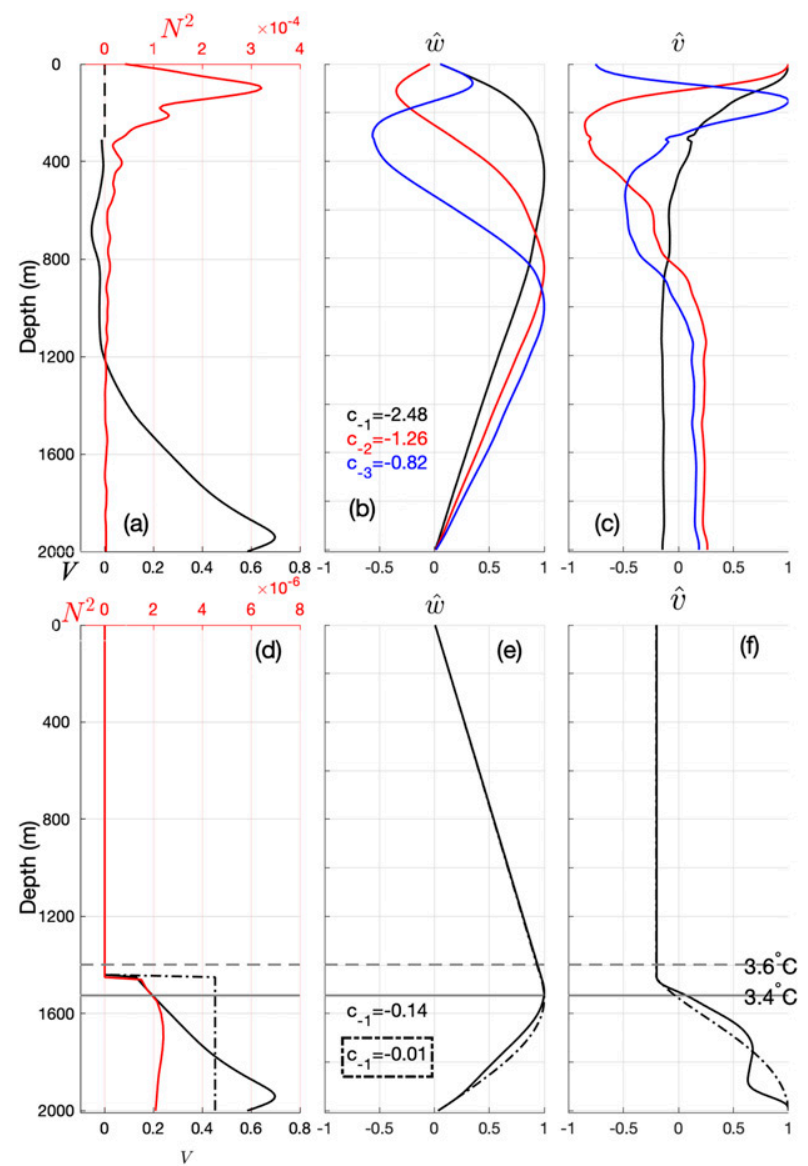

FIG. 4. Modal structure of selected normalized eigenvectors $\hat{w}(z)$ and $\hat{v}(z)$ as determined by the numerical solution of the TaylorGoldstein equation. The vertical modes correspond to upstream propagating waves $(j=-1,-2,-3)$. (a) The full-depth squared buoyancy frequency profile $N^{2}\left(\mathrm{~s}^{-2}\right)$ from CTD measurements (red) and the velocity profile $V\left(\mathrm{~m} \mathrm{~s}^{-1}\right)$ from mooring measurements (black), while the dashed line indicates that the velocity profile above $300 \mathrm{~m}$ is filled with zeros. (b), (c) Vertical structure of the three modes in terms of $\hat{w}(z)$ and $\hat{v}(z)$, respectively, based on the profiles in (a). (d) The modified stratification and velocity profiles. The stratification profile (red) assumes a homogenous upper layer. The solid and dash-dotted velocity profiles (black) assume an inactive layer placed above a moving layer with depthdependent and uniform velocities, respectively. (e),(f) The gravest modes $(j=-1)$ of the profiles in (d). The solid and dash-dotted modes in (e) and (f) are based on the solid and the dash-dotted velocity profiles in (d), respectively. Phase speeds are color-coded and listed with units of $\mathrm{m} \mathrm{s}^{-1}$, with the negative sign representing upstream propagation. The dashed and solid lines in (d)-(f) indicate the locations of the $\Theta=3.6^{\circ}$ and $3.4^{\circ} \mathrm{C}$ surfaces, respectively.

at $2000 \mathrm{~m}$ as the lower boundary where a free-slip boundary condition (nonzero velocity) is implied. This choice of boundary condition for the background flow is consistent with the inviscid TG equation for disturbances. The Richardson number is greater than $1 / 4$ at nearly all $z$ for this profile, with just a few values lying 
slightly below $1 / 4$. Were it the case that the Richardson number was greater than $1 / 4$ at all $z$, it is known that an infinite number of discrete vertical modes $\hat{w}_{j}(z)$ and corresponding eigenvalues $c_{j}$ exists (Drazin and Reid 1981; Baines 1995). Each mode comes in a pair [denoted $\hat{w}_{j}(z)$ and $\left.\hat{w}_{-j}(z)\right]$, corresponding to waves that attempt to propagate downstream and upstream relative to the mean flow. Figures $4 \mathrm{~b}$ and $4 \mathrm{c}$ show that the gravest vertical modes of the full-depth profiles are largely determined from the strongly stratified subsurface layer $(\sim 100 \mathrm{~m})$ and correspond to waves propagating on a shallow waveguide. They are insensitive to the velocity and stratification within the deep overflow. Modes $j=-1,-2$, and -3 have negative propagation speeds in the range -0.82 to $-2.48 \mathrm{~m} \mathrm{~s}^{-1}$, suggesting that they are able to propagate from the Seram Sea to the Maluku Sea unimpeded. The generalized Scorer parameter $l^{2}$ (Figs. 5a-c) shows the largest positive values dominated by the stratification term in the upper part of the water column at around $100 \mathrm{~m}$, suggesting that the large nearsurface stratification provides the primary restoring tendency to the corresponding waves. It should be noted that the velocity profile above $300 \mathrm{~m}$ is arbitrarily filled with zeros, but the upstream propagation tendency would not be affected unless the shallow velocities were positive and approached the propagation speeds listed above.

Identification of the waves whose upstream propagation is arrested by the overflow, and that are therefore hydraulically relevant, is more problematic. There are many modes with large numbers of zero-crossings that have near-zero phase speed and are arrested, or nearly so, by the deep flow, and therefore are difficult to interpret (e.g., Pratt et al. 2000; Hogg et al. 2001). However, the situation may be simplified by invoking an argument that has its origins in literature pertaining to mountain waves and downslope winds (Smith and Sun 1987): the top of the descending flow is often subject to shear instabilities and overturns that may lead to a homogenized layer of fluid (e.g., Peltier and Clark 1979; Pawlak and Armi 1997; Farmer and Armi 1999), and the base of this layer tends to act as a perfect reflector of internal waves, implying that the spilling layer is insulated from properties of the flow above and may be treated in isolation. The wave modes relevant to the spilling layer may then be found by treating the fluid within and above the mixed layer as homogeneous. Figures $3 a$ and $3 b$ suggest the presence of a weakly stratified (though not completely mixed) layer between $\Theta=3.6^{\circ}$ and $3.4^{\circ} \mathrm{C}$. We will treat the base of this layer as the interface bounding the spilling flow and will solve the TG equation in the lower portion of the water column using a pliant boundary condition at that
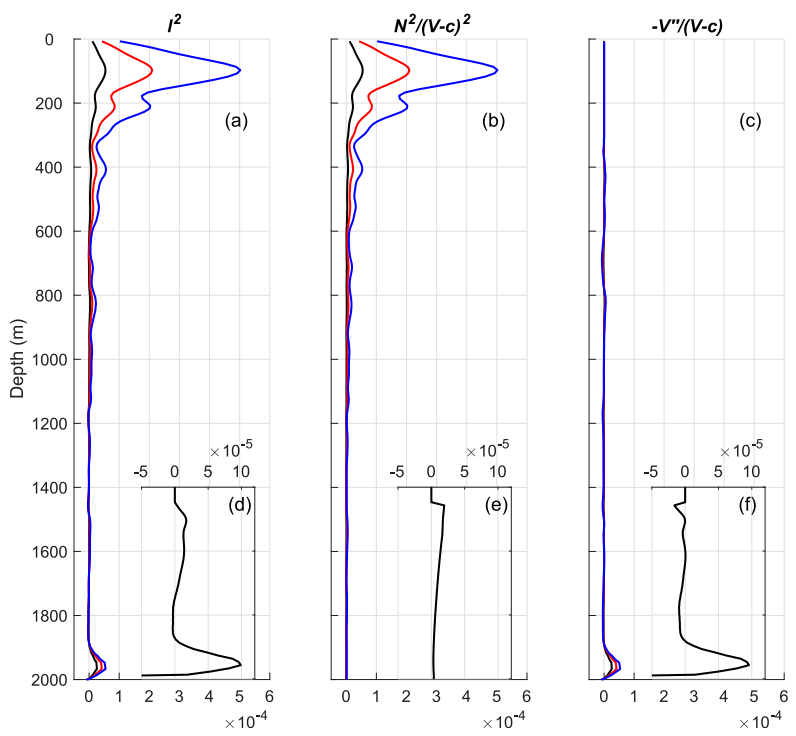

FIG. 5. (a)-(c) Color-coded generalized Scorer parameter $l^{2}=$ $N^{2} /(V-c)^{2}-V^{\prime \prime} /(V-c)$ (unit of $\left.\mathrm{m}^{-2}\right)$ and its first and second constituents for modes $(j=-1,-2,-3)$ based on the full-depth stratification and velocity. (d)-(f) As in (a)-(c), but for the mode $(j=-1)$ obtained from the modified stratification and velocity profiles indicated by the solid curves in Fig. 4d. Note that the maxima of the generalized Scorer parameters shown in (d)-(f) can be an order of magnitude smaller than those in (a)-(c), and plots in (d)-(f) are limited to depths below $1400 \mathrm{~m}$.

interface. A pliant surface is a material interface separating the stratified fluid from the homogenous layer above, and across which the pressure is continuous (see section 1.2 in Baines 1995). This procedure is tantamount to solving the TG equation over the full depth, but replacing the fluid above the bottom of the mixed layer with a homogeneous, inactive layer. We use the time-mean profiles of $N^{2}$ and $V$ from mooring measurements, with estimated Richardson numbers mostly larger than 1/4 within the overflow (Fig. 3d).

Sensitivity tests were made by choosing different levels between $\Theta=3.6^{\circ}$ and $3.4^{\circ} \mathrm{C}$ as the interface. Profiles of $V$ and $N^{2}$ for one such choice along with profiles of the corresponding gravest mode are given by solid curves in Figs. 4d-f. Each choice of interface yields a gravest mode $(j=-1)$ with maximum amplitude of $\hat{w}_{-1}$ and zero-crossing of $\hat{v}_{-1}$ located at the same level around the interface of the overflow (within the range of $\Theta=3.4^{\circ}-3.6^{\circ} \mathrm{C}$ ). The waves so obtained all propagate slowly upstream, with speeds $c_{-1}$ ranging from -0.08 to $-0.17 \mathrm{~m} \mathrm{~s}^{-1}$. To put these values into context, an equivalent Froude number $V /\left(V-c_{-1}\right)$ (a ratio of the flow speed and the phase speed of the first baroclinic mode for a quiescent fluid), where $V=$ $0.45 \mathrm{~m} \mathrm{~s}^{-1}$ is the layer-average velocity, would lie in the range $0.73-0.85$, which is only slightly below the range of 
estimates for layer-model Froude numbers given earlier. For comparison, we also show the solution of the TG equation with uniform overflow velocities (black dashdotted velocity profile and vertical modes in Figs. 4d-f). The wave propagation speed of mode $j=-1$ is found to be very close to zero $\left(c_{-1}=-0.01 \mathrm{~m} \mathrm{~s}^{-1}\right)$, which is consistent with the estimate of $-0.03 \mathrm{~m} \mathrm{~s}^{-1}$ assuming uniform $N^{2}$ and $V$ (see section 3b). Interestingly, we find that the effects of shear on the structure of deep modes are particularly pronounced near the bottom. As shown in Figs. $5 \mathrm{~d}-\mathrm{f}$, the generalized Scorer parameter $l^{2}$ of the shear flow is positive and dominated by the velocity curvature term, suggesting that the vorticity gradient provides the main restoring tendency for the corresponding waves.

\section{Mixing and entrainment}

The Conservative Temperature section (Fig. 2) shows features of an internal hydraulic jump in the $\Theta=3.6^{\circ} \mathrm{C}$ surface rebound near CTD site 6 . It also reveals two weakly stratified, wedge-like structures bounded by $\Theta=$ $3.8^{\circ}$ and $3.6^{\circ} \mathrm{C}$ between CTD sites 3 and 6 , and by $\Theta=$ $3.4^{\circ}$ and $3.2^{\circ} \mathrm{C}$ between CTD sites 4 and 7 , respectively. The former mixed wedge is located above the spilling overflow. The latter is marked with "MW" in Fig. 2 and its upper surface is later used to define the entrainment interface. Mixed wedges are common in other examples of oceanic and atmospheric overflows (e.g., Peltier and Clark 1979; Pawlak and Armi 1997; Farmer and Armi 1999). The above characteristics suggest vigorous turbulent mixing downstream of the hydraulic control section, which may lead to amplification of the volume transport of the downstream overflow plume during its descent.

In this section, we attempt to evaluate the diapycnal mixing and entrainment downstream of the Lifamatola Passage, and then infer ventilation, mixing, and turbulent heat flux in the downstream Banda Sea basin. We assume that the diapycnal mixing is approximately the mixing normal to isotherms since density is mostly controlled by temperature in this region.

\section{a. Estimates of diapycnal mixing coefficients}

We estimated the interfacial mixing of the Lifamatola Passage overflow by evaluating Thorpe-scale overturning lengths from CTD casts. Diapycnal diffusivity estimates have also been made from the mass and heat budgets integrated over control volumes. The former are local estimates, and the later provide a spatial integral view of the mixing.

\section{1) Thorpe-scale-based estimates}

One widely used estimate of the turbulent dissipation rates is based on Thorpe scales (Thorpe 1977), which assumes that the density inversions are due to the turbulent mixing. The turbulent dissipation rates $\varepsilon$ and corresponding diapycnal diffusivity coefficients $K$ of individual overturns, shown in Fig. 6a, were estimated at all nine CTD stations using Thorpe scales estimated from Conservative Temperature profiles and Osborn's model for the relationship between $\varepsilon$ and $K$ (details are described in appendix B). Identified overturns with large $\varepsilon$ and $K$ are found concentrated downstream of the crest of the sill, while fewer overturns and weaker mixing are found upstream of the crest. At CTD sites 5 and 6 , regions of large overturns are separated by the $\Theta=3.4^{\circ} \mathrm{C}$ isotherm, which is associated with the two mixed wedges described above (also seen in Fig. 2). High mixing levels are also found within the descending flow downstream of the CTD site 6 , but weaker values are seen at the final section (CTD site 9), where the flow is laterally unconfined by bathymetry.

To assess the spatial variation of dissipation rates across the sill, we calculated the depth average of the dissipation rate within the overflow as

$$
\bar{\varepsilon}=\frac{1}{H} \sum_{i} \varepsilon_{i} h_{i},
$$

where $H$ is the thickness of the overflow, $\varepsilon_{i}$ and $h_{i}$ are the dissipation rate and thickness of an individual overturn within the overflow layer. The upper boundary of the overflow was chosen to be the $\Theta=3.4^{\circ} \mathrm{C}$ isotherm since the time-mean overflow velocities at the mooring location are found mostly confined below this isotherm and it is a convenient choice for doing the budget calculation detailed in sections $4 \mathrm{~b}$ and $4 \mathrm{c}$. In regions where no overturns were detected, we alternatively assume a background $\varepsilon$ of zero and $0.2 \times 10^{-7} \mathrm{~W} \mathrm{~kg}^{-1}$, and we compute the corresponding lower and upper bounds of $\bar{\varepsilon}$. The value $0.2 \times 10^{-7} \mathrm{~W} \mathrm{~kg}^{-1}$ is different from a typical oceanic background level of $O\left(10^{-10}\right) \mathrm{W} \mathrm{kg}^{-1}$ [observed in the abyssal Brazil basin by St. Laurent et al. (2001)]: instead, it indicates the upper limit for unresolved overturns (with Thorpe scales smaller than $1 \mathrm{~m}$ ) and is calculated using the maximum background buoyancy frequency of $N=3 \times 10^{-3} \mathrm{~s}^{-1}$ determined from the resolved overturning regions within the overflow. A corresponding estimate of the upper limit of $K$ for unresolved overturns is $0.4 \times 10^{-3} \mathrm{~m}^{2} \mathrm{~s}^{-1}$. As shown in Fig. $6 \mathrm{~b}$, the highest values of $\bar{\varepsilon}(0.6-1.1 \times$ $10^{-7} \mathrm{~W} \mathrm{~kg}^{-1}$ ) are found immediately downstream the crest of the sill (CTD sites 5-7), where the mixed wedge is located and hydraulic jumps are suggested, while the regions upstream and further downstream have smaller $\bar{\varepsilon}$. The differences between upper and lower bounds of $\bar{\varepsilon}$ at these locations are less than $0.1 \times 10^{-7} \mathrm{~W} \mathrm{~kg}^{-1}$. 


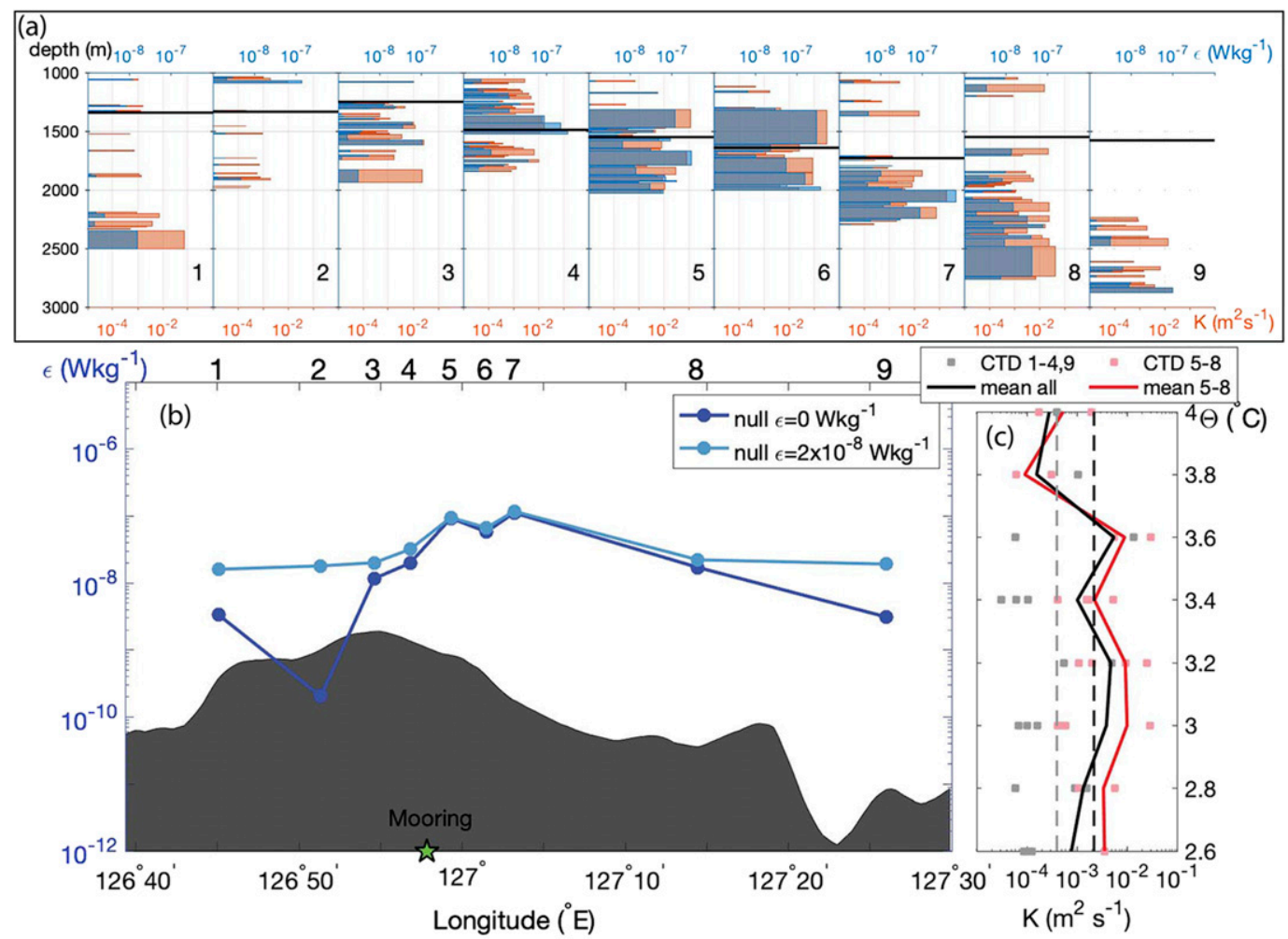

FIG. 6. (a) Estimates of $\varepsilon$ (blue bars) and $K$ (orange bars) for each overturn at CTD sites 1-9, with black lines indicating the levels of the $\Theta=3.4^{\circ} \mathrm{C}$ isotherm. (b) The mean overflow dissipation rates across the sill. The depth averages were calculated using a zero and nonzero background dissipation coefficient. (c) Diapycnal diffusivity coefficients from overturns averaged into isothermal layers (squares) and over all the CTD sites (black line) and CTD sites 5-8 (red line), respectively. The gray and black dashed lines indicate the diffusivity coefficients for unresolved overturns and estimated in the deep Banda Sea by van Aken et al. (2009), respectively.

The spatial pattern seen in the mean overflow dissipation rates is also found in the diapycnal diffusivity coefficient averaged over isothermal layers $\bar{K}$ within the overflow (Fig. 6c). The layer average is calculated as

$$
\bar{K}=\frac{1}{\Delta \Theta} \sum_{i} K_{i} \delta \Theta_{\iota},
$$

where $\Delta \Theta=0.2^{\circ} \mathrm{C}$ is the temperature spacing, and $K_{i}$ and $\delta \Theta_{i}$ are the diffusivity coefficient of an overturn and the change of the sorted Conservative Temperature values across the overturning region, respectively. The value of $\bar{K}$ was calculated within layers centered at isotherms ranging from $2.6^{\circ}$ to $4.0^{\circ} \mathrm{C}$. The values of $\bar{K}$ averaged over CTD sites 5-8 are 2.0-4.6 times of those averaged over all profiles within layers below the overflow interface (the $3.4^{\circ} \mathrm{C}$ isotherm), suggesting an enhancement in tracer diffusion immediately downstream of the mooring, although the averages are subject to large uncertainties due to the very small set of data (e.g., only four overturns are identified within the layer $\left.2.6^{\circ} \pm 0.1^{\circ} \mathrm{C}\right)$. In fact, following the standard error propagation methods (Bevington and Robinson 1992), the standard error of the mean is estimated to be larger than the region averages. However, the means still lie well above the maximum value of diffusivity for unresolved overturns (gray dashed line in Fig. 6c), and using this background $K$ only increase the results by at most $1 \times 10^{-3} \mathrm{~m}^{2} \mathrm{~s}^{-1}$. The diffusivity coefficients averaged over CTD sites $5-8$ range from $2.3 \times 10^{-3}$ to $10.1 \times 10^{-3} \mathrm{~m}^{2} \mathrm{~s}^{-1}$ within the overflow layer, and these values are 1-5 times of the bulk estimate in the deep Banda Sea, $2.2 \times 10^{-3} \mathrm{~m}^{2} \mathrm{~s}^{-1}$ given by van Aken et al. (2009). This suggests that a mixing hotspot is located downstream of the hydraulically controlled sill in the Lifamatola Passage. We caution that the correlations between temperature gradients and local diffusivity coefficients can significantly affect the actual region-averaged dispersion. Using an approach presented by Wagner et al. (2019), we estimate that the spatial variation of temperature gradients can modulate the diffusivity coefficient averaged across the sill by a factor 
ranging from 0.7 to 1.6 for layers within the overflow. Our data do not have the resolution in time and space required to assess whether and in which layer this factor would be statistically significantly different from one.

\section{2) Estimates based ON THE THERMODYNAMIC BUDGET}

As an alternative, we can make a bulk estimate of the interfacial diapycnal diffusivities assuming the advective fluxes of a water property are balanced by the diffusive fluxes (Hogg et al. 1982; Whitehead and Worthington 1982). Here we chose the water property to be the Conservative Temperature $\Theta$. The conservation laws and procedure, which are described in detail in appendix $\mathrm{C}$, involve identification of a control volume that is bounded upstream by the vertical cross section at the mooring site, above by the $\Theta=2.6^{\circ} \mathrm{C}$, and below by the seafloor.

The reason why we choose to work with the $\Theta=2.6^{\circ} \mathrm{C}$ isotherm is that it was detected very close to the bottom at CTD site 8. However, the actual surface is not well constrained due to the lack of measurements near the sea bottom and to the coarse resolution of the CTD casts. Two plausible estimates of the depths of the $\Theta=$ $2.6^{\circ} \mathrm{C}$ isotherm along the thalweg can be made based on available data and interpolation. One choice is to draw a polyline (black dashed line in Fig. 2) connecting all the three locations where the overflow of $\Theta=2.6^{\circ} \mathrm{C}$ has been observed (the mooring station, CTD sites 5 and 8 ). Another estimate is to include an additional data point from CTD site 7 (red dashed line in Fig. 2): there the deepest measurement $\left(\Theta=2.7^{\circ} \mathrm{C}\right)$ was taken within $50 \mathrm{~m}$ from the bottom, and we assume the layer below this depth contains waters with $\Theta \leq 2.6^{\circ} \mathrm{C}$

The diapycnal diffusivity coefficient $K$ estimated from two control volumes ranges, $2 \times 10^{-2}-9 \times 10^{-2} \mathrm{~m}^{2} \mathrm{~s}^{-1}$ and $2 \times 10^{-2}-11 \times 10^{-2} \mathrm{~m}^{2} \mathrm{~s}^{-1}$ [Eq. (C3)], both computed using volume and heat fluxes based on the assumption of laterally uniform velocity. For the jet-like velocity distribution mentioned in section $3 a$, based on the same definitions of the control volume, $K$ lies in the ranges $1 \times 10^{-2}-5 \times 10^{-2} \mathrm{~m}^{2} \mathrm{~s}^{-1}$ and $1 \times 10^{-2}-6 \times$ $10^{-2} \mathrm{~m}^{2} \mathrm{~s}^{-1}$. The contribution from the dissipation term is less than $10^{-6} \mathrm{~m}^{2} \mathrm{~s}^{-1}$. The range of $K$ mostly results from the uncertainties in the estimate of the spatialaverage interfacial enthalpy gradients $\left.\left(\partial h^{\mathrm{o}} / \partial z\right)\right|_{(i)}$, which is determined from the enthalpy gradients at CTD site 5 and at the mooring station using first-order differences with grid size ranging from 4 to $200 \mathrm{~m}$. We disregard the value at CTD site 8 since the $\Theta=2.6^{\circ} \mathrm{C}$ isotherm approaches the bottom there. The estimate based on the potential enthalpy budget gives a spatial-average view of the mixing over the $\Theta=2.6^{\circ} \mathrm{C}$ surface spanning from the crest of the sill to the downstream where it grounds, and is an order of magnitude greater than the regionaveraged estimates from Thorpe scales.

\section{b. Entrainment estimate}

An important consequence of mixing around the interfacial region is the downward entrainment of mass into the overflow and the consequential increasing transport. For the 1.5-layer model configuration, the entrainment process can be represented by a velocity component across the interface separating the layers (Gerdes et al. 2002). For a continuously stratified overflow, identification of the boundary across which entrainment is measured is less clear. Here we choose the $\Theta=3.4^{\circ} \mathrm{C}$ surface as a reasonable interface and define a lower-layer control volume that is bounded above by this surface and extends from the mooring section downstream to CTD site 7 or 8 . This definition distinguishes the water that sinks to great depth in the Banda Sea from water that moves towards the Banda Sea but does not sink appreciably. Other choices of the interface are certainly possible. As detailed in appendix $\mathrm{C}$, the downward entrainment across this interface can be estimated by again combining budgets for mass and potential enthalpy. The lack of direct velocity data at the downstream section requires an approximation, namely, that the potential enthalpy flux there is equal to the depth-average potential enthalpy, which we know, times the vertical integral of the horizontal velocity, which is not known. This simplification allows us to eliminate the unknown velocity integral and close the problem.

Use of the above procedure, with the depth-average potential enthalpy at the downstream section estimated from the vertical arithmetic mean and area-weighted mean, yields volume entrainment rates of $0.6-0.7$ and 1.0-1.2 Sv, respectively [Eq. (C4)]. The gap between the two estimates indicates the uncertainty of the estimated entrainment due to lack of knowledge of the downstream velocity profile. The results are relatively insensitive to the diapycnal diffusivity along the interface, the choices of downstream sections, and the dissipation rate within the control volume. Summing the overflow transport $(2.4 \mathrm{~Sv})$ at the mooring station and the downstream entrainment yields a total volume flux of $3.0-3.6 \mathrm{~Sv}$ below $\Theta=3.4^{\circ} \mathrm{C}(\sim 1500 \mathrm{~m}$ at mooring location $)$. The updated overflow transport is about $20 \%-40 \%$ larger than the $2.5 \mathrm{~Sv}$ below $1250 \mathrm{~m}$ estimated by van Aken et al. (2009), which includes some water above $\Theta=3.4^{\circ} \mathrm{C}$ that may not be affected by entrainment as it moves downstream.

\section{c. Ventilation, mixing, and turbulent heat flux in the Banda Sea}

The cold deep branch of the ITF passes through the Lifamatola Passage, descends into the deep Banda Sea, 
and is thought to account for the deep ventilation in that basin (Wyrtki 1961; Gordon et al. 2003b; van Aken et al. 1988, 2009). A mean upwelling velocity of $50 \mathrm{~m} \mathrm{yr}^{-1}$, responsible for the deep-water renewal, was estimated by van Aken et al. (1988) using a deep transport estimate of $1 \mathrm{~Sv}$ below $1500 \mathrm{~m}$ divided by the surface area of the Banda Sea. This transport was later updated to $2.5 \mathrm{~Sv}$ by van Aken et al. (2009) leading to a proportionally larger upwelling of $125 \mathrm{~m} \mathrm{yr}^{-1}$. From the 72 WOCE profiles, the average depth of the $\Theta=3.4^{\circ} \mathrm{C}$ surface in the Banda Sea lies at $1555 \pm 84 \mathrm{~m}$ (with uncertainties represented by one standard derivation) and the corresponding area is $(6.1 \pm 0.1) \times 10^{11} \mathrm{~m}^{2}$. Substituting the interface area at the average depth of the $\Theta=3.4^{\circ} \mathrm{C}$ surface, our estimated mooring transport of $2.4 \mathrm{~Sv}$, plus the entrainment of $0.6-1.2 \mathrm{~Sv}$ into Eq. (C5) yields an upwelling rate of $\sim 160-190 \mathrm{~m} \mathrm{yr}^{-1}, 25 \%-50 \%$ larger than the value without entrainment.

Van Aken et al. $(1988,2009)$ estimated the diapycnal diffusivity coefficient in the Banda Sea using the approach of Munk (1966) in which an advection-diffusion length scale is estimated from data. Their early estimate $9 \times 10^{-4} \mathrm{~m}^{2} \mathrm{~s}^{-1}$, valid for an inflow of $1 \mathrm{~Sv}$, was later raised to $2.2 \times 10^{-3} \mathrm{~m}^{2} \mathrm{~s}^{-1}$ in accordance with their revised transport estimate of $2.5 \mathrm{~Sv}$. Here we present a slightly different estimate based on the mass and thermodynamic budgets for a control volume that is bounded upstream by CTD site 8 and above by the $\Theta=3.4^{\circ} \mathrm{C}$ surface, which is topographically confined within the Banda Sea. Note that any downward entrainment downstream of mooring station would eventually upwell across the same $\left(\Theta=3.4^{\circ} \mathrm{C}\right)$ surface and would therefore not alter the thermodynamic budget. The control volume is shown schematically in Fig. $\mathrm{C} 1$ and the calculation is detailed in appendix B. The estimated diapycnal diffusivity coefficient over the $\Theta=3.4^{\circ} \mathrm{C}$ surface is $1.6 \times 10^{-3} \pm 5 \times$ $10^{-4} \mathrm{~m}^{2} \mathrm{~s}^{-1}$, with uncertainties (one standard error) mostly due to the unknown spatial dependence of the vertical gradient of the potential enthalpy at the upper boundary of the control volume. The contribution from the uncertainty of area is on the order of $10^{-5} \mathrm{~m}^{2} \mathrm{~s}^{-1}$. The potential enthalpy profiles calculated from the WOCE measurements were subsampled onto a $100-\mathrm{m}$ grid. The vertical gradients were computed using first differences at midpoints of bins and then interpolated to desired levels.

Based on the same control volume, we estimate a downward turbulent heat flux of $9 \mathrm{~W} \mathrm{~m}^{-2}$ at the $\Theta=3.4^{\circ} \mathrm{C}$ surface [Eq. (C8)]. Van Aken et al. (2009) proposed that a downward heat flux of $28 \mathrm{~W} \mathrm{~m}^{-2}$ is required to support upwelling of the cold deep branch of ITF from below $1250 \mathrm{~m}\left(\sim 3.2^{\circ} \mathrm{C}\right)$ to about $1000 \mathrm{~m}\left(\sim 5.0^{\circ} \mathrm{C}\right)$ in the Banda Sea, from whence it can enter the Indian Ocean. Their estimate assumes that no flow passes through the
Lifamatola Passage between the two depths, although the same authors reported a $\sim 1.4-\mathrm{Sv}$ northward flux above $1250 \mathrm{~m}$. Their estimate would be lower if the advective heat flux above the overflow were included (Gordon et al. 2010). Our estimate of turbulent heat flux avoids the assumption of zero advective heat fluxes above the overflow layer and instead provides an estimate of the heat flux required to maintain the stratification at the level of the $\Theta=3.4^{\circ} \mathrm{C}$ isothermal surface in the Banda Sea.

\section{Conclusions and discussions}

In this study, we use hydrographic data from a recent cruise in combination with hydrographic and velocity data from the INSTANT mooring to study the hydraulic control of the Lifamatola Passage deep overflow and the associated mixing and entrainment downstream. The Froude numbers and long wave modes of the flow suggest that the overflow is near-critical slightly downstream of the sill. Hydrographic measurements from full-depth CTD casts show deep waters spilling over the sill crest and descending along the downstream slope of the Lifamatola Passage, suggesting a supercritical overflow. Intense mixing downstream of the sill is suggested by plentiful finescale density inversions in the CTD profiles. The spilling overflow entrains overlying waters along its path, as a consequence of mixing, and enters the deep Banda Sea, where it upwells and exits to the Indian Ocean.

Our estimate of $2.4 \mathrm{~Sv}$ of volume transport below the $3.4^{\circ} \mathrm{C}$ Conservative Temperature surface agrees moderately well with results from all three of the idealized weir formulas for critical flow, although most closely with the rectangular or triangular weir formulas. Based on Thorpe scale estimates, we find that for the overflow delimited by the $3.4^{\circ} \mathrm{C}$ interface, the mean dissipation rate is up to $1.1 \times 10^{-7} \mathrm{~W} \mathrm{~kg}^{-1}$ downstream of the mooring location and the diapycnal averaged diffusivity averaged over downstream isothermal layers ranges from $2.3 \times 10^{-3}$ to $10.1 \times 10^{-3} \mathrm{~m}^{2} \mathrm{~s}^{-1}$. A bulk diapycnal diffusivity estimated from a thermodynamic budget ranges from $2 \times 10^{-2}$ to $11 \times 10^{-2} \mathrm{~m}^{2} \mathrm{~s}^{-1}$ at the $2.6^{\circ} \mathrm{C}$ interface. This mismatch may be caused by lack of hydrographic measurements near the $2.6^{\circ} \mathrm{C}$ interface. The associated entrainment transport is estimated to be 0.6-1.2 Sv, bringing the total overflow transport of water colder than $3.4^{\circ} \mathrm{C}$ to $3.0-3.6 \mathrm{~Sv}$. The diapycnal diffusivity coefficient and downward turbulent heat flux required to reach thermal equilibrium with the upwelling cold water are $1.6 \times 10^{-3} \pm 5 \times 10^{-4} \mathrm{~m}^{2} \mathrm{~s}^{-1}$ and $9 \mathrm{~W} \mathrm{~m}^{-2}$ at the $3.4^{\circ} \mathrm{C}$ surface within the Banda Sea.

Van Aken et al. (2009) estimated that tidal currents account for $\sim 65 \%$ of the along-thalweg current variability 

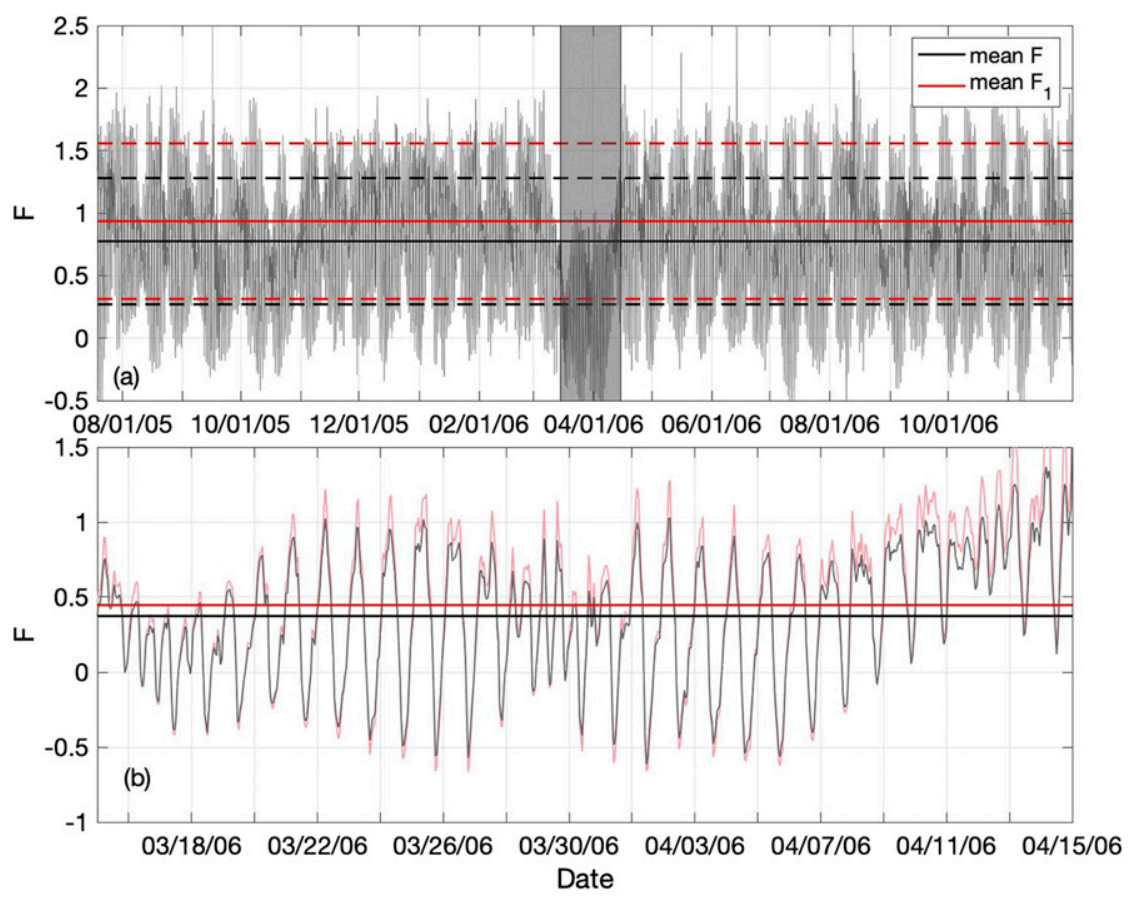

FIG. 7. (a) Hourly Froude numbers $F$ of the 1.5 -layer model. $F_{1}$ (for stratified flow with constant $N$ ) is generally 1.2 times of $F$ and varies in a fashion similar to $F$ (correlation coefficient of $\sim 0.99$ ), thus is not shown. The time means of $F$ and $F_{1}$ are represented by the black and red solid lines, respectively. The dashed lines are one standard deviation of the time series (black lines for $F$ and or red lines for $F_{1}$ ). (b) A zoom-in of the Froude number time series and time means ( $F$ in black, $F_{1}$ in red) from 15 Mar to 15 Apr 2006 [gray shading in (a)].

at the mooring location, but they also identified a monthlong record when hydrographic properties in the passage were substantially altered by an intrusion of an anomalous water mass from the Maluku Sea into the passage. The effect of tidal variations on the criticality of the flow can be evaluated by the Froude numbers $F$ and $F_{1}$ (section 3b) assuming the upper boundary of the overflow at $\Theta=3.4^{\circ} \mathrm{C}$. As shown in Fig. 7a, the time-mean values for both $F$ and $F_{1}$ are close to unity, but their standard deviation is close to 0.5 , suggesting potential interruptions of hydraulic control. Instantaneous Froude numbers above and below unity suggest moderately subcritical and supercritical flows over a typical tidal cycle, but these fluctuations may correspond to a shift in the position of the critical section rather than a complete loss of criticality. However, a substantial reduction in Froude number values occurred during the month-long episode (Fig. 7b) identified by van Aken et al. (2009). Further investigation of time dependence is beyond the scope of this work but remains a largely open area of investigation.

Although the gradient Richardson numbers calculated from the mean profiles are generally larger than the critical value $1 / 4$, a few instantaneous values near the bottom are below 1/4 (10th-percentile profile in Fig. 3d), which may indicate presence of shear instabilities (Miles 1961; Howard 1961) of the intermittent flow. The proximity of the passage to the equator also raises the question of whether inertial instability might occur. If a background flow is parallel and inviscid, this flow is geostrophic balanced and the necessary condition for submesoscale instability in the Southern Hemisphere is

$$
q=\frac{1}{g}\left[\left(f+\frac{\partial V}{\partial x}\right) N^{2}-f\left(\frac{\partial V}{\partial z}\right)^{2}\right]>0,
$$

where $f$ is the Coriolis parameter and $q$ is the Ertel potential vorticity (Hoskins 1974). Inertial instability is favored when the term involving the absolute vertical vorticity (first term) is dominantly positive. Here we assume that the Lifamatola velocity field at the mooring section is parallel and directed along the thalweg, and rotate coordinates so that $x$ in Eq. (7) indicates crossthalweg direction. Assuming the background overflow is geostrophic and jet-like, with $V$ of $0.45 \mathrm{~m} \mathrm{~s}^{-1}, N^{2}$ of $2 \times 10^{-6} \mathrm{~s}^{-2}, f$ of $-4.6 \times 10^{-6} \mathrm{~s}^{-1}$, and the horizontal and vertical scales of $10 \mathrm{~km}$ and $500 \mathrm{~m}$, respectively, we estimate $q=\left[1.7 \times 10^{-11}+4 \times 10^{-13}\right]>0$, which 
suggests that inertial instability is possible. Condition (7) is only satisfied within the northeast portion of the jetlike flow, and the fastest growing disturbance is estimated to be $2 \pi / 3.6$ days based on Thomas et al. (2013). We note that the assumption of geostrophy may lead to an unrealistic simplification of $q$ in Eq. (7), since the channel width $(\sim 21 \mathrm{~km})$ is many times smaller than the local Rossby radius of deformation $(\sim 124 \mathrm{~km})$ and thus the ageostrophic components of the background flow may be nonnegligible. Future high-resolution velocity and hydrographic measurements across the passage could determine the extent to which the flow is geostrophically balanced. Inertial instability might result in meandering of the flow, or perhaps cellular motions in the plane normal to the flow axis, and would therefore be difficult to detect using the present data.

Acknowledgments. This study is supported by NSFC (91858204), the CAS Strategic Priority Research Program (XDB42000000), NSFC (41720104008, 41421005, 41876025), QMSNL (2018SDKJ0104-02), and the Shandong Provincial projects (U1606402). L. Pratt was supported by the U.S. NSF Grant OCE-1657870. The authors thank the crews of R/V BJ8 and the technicians from RCO-LIPI for the successful cruises. We thank the INSTANT and WOCE programs for making datasets publicly available and William D. Smyth for sharing the MATLAB toolbox for solving the Taylor-Goldstein equation. We also thank the insightful comments from Matthew H. Alford and Gunnar Voet. S. Tan was supported by Chinese Scholarship Council. The authors thank two anonymous reviewers for their comments.

\section{APPENDIX A}

\section{The "Shape" Coefficients}

The "shape" coefficients that account for vertical variations in velocity and density are defined following Nielsen et al. (2004):

$$
\begin{aligned}
\alpha & =\frac{\int_{h}^{h+D} v(z)^{2} d z}{D V^{2}}, \\
\beta & =\frac{2 \int_{h}^{h+D} \int_{z}^{h+D} \rho^{\prime}\left(z^{\prime}\right) d z^{\prime} d z}{D^{2} \bar{\rho}^{\prime}},
\end{aligned}
$$

where $V=\int_{h}^{h+D} v(z) d z / D, \bar{\rho}^{\prime}=\int_{z}^{h+D} \rho^{\prime}(z) d z / D, h$ is the bottom depth, and $\rho^{\prime}(z)=\rho(z)-\rho_{0}$ is the difference between density at $z$ and the density of a homogeneous overlying layer.

\section{APPENDIX B}

\section{Diapycnal Diffusivity and Turbulent Dissipation from Thorpe Scales}

The Thorpe scale $L_{T}$ is defined as the root-meansquare of the vertical displacements (Thorpe displacements) required re-sorting of the density profile to form a stable configuration (Thorpe 1977). In order to remove the noise associated with salinity spikes, we compute the Thorpe displacements based on Conservative Temperature instead of density from CTD measurements. Another justification for using temperature profiles is that the temperature sensor has a lower noise level than the conductivity sensor. We note that $90 \%$ of the density stability ratios $R_{\rho}$ within overturns are less than -3.0 , suggesting that the overturns are primarily temperaturestratified. The ratio $R_{\rho}$ quantifies the relative contributions of the vertical gradients of temperature and salinity to the stratification, and a range of -0.5 to 2.0 has been used to identify salinity-stratified overturns and salt fingers (St. Laurent and Schmitt 1999; Ijichi and Hibiya 2018). An overturn is delimited by its upper and lower boundaries, where the cumulative Thorpe displacements become zero. Limited by the CTD resolution (about $1 \mathrm{~m}$ ), we can only resolve overturns that are larger than $2 \mathrm{~m}$ or Thorpe scales $L_{T}$ larger than $1 \mathrm{~m}$. Also, we employ the procedure developed by Thorpe (1977) of rejecting any overturn in which the sorted profile differs from the original profile by less than the noise level. This is done to avoid introducing spurious overturns and upward biasing of the dissipation rate estimates. The noise level of the Conservative Temperature is taken to be the CTD accuracy for temperature, $0.001^{\circ} \mathrm{C}$

The dissipation rate of turbulent kinetic energy $\varepsilon$ can be estimated under the assumed linear relationship of $L_{T}$ and Ozmidov scale $L_{O}$ (Ozmidov 1965):

$$
\varepsilon=a^{2} L_{T}^{2} N^{3},
$$

where $a=L_{O} / L_{T}$ is the proportionality factor and $L_{O}=\varepsilon^{1 / 2} N^{-3 / 2}$ is the Ozmidov scale, the expected vertical scale of the largest possible overturn. We choose $a=0.8$, which holds under a range of different oceanic mixing conditions (Dillon 1982). $N$ is the background buoyancy frequency, against which the turbulence works. Since the Conservative Temperature is used as a surrogate for density, "pseudo" potential density profiles constructed only from temperature measurements are used to estimate $N$ (Mater et al. 2015). Following Smyth et al. (2001), $N$ in an overturning region is calculated from a bulk density gradient defined by the root-mean-square 


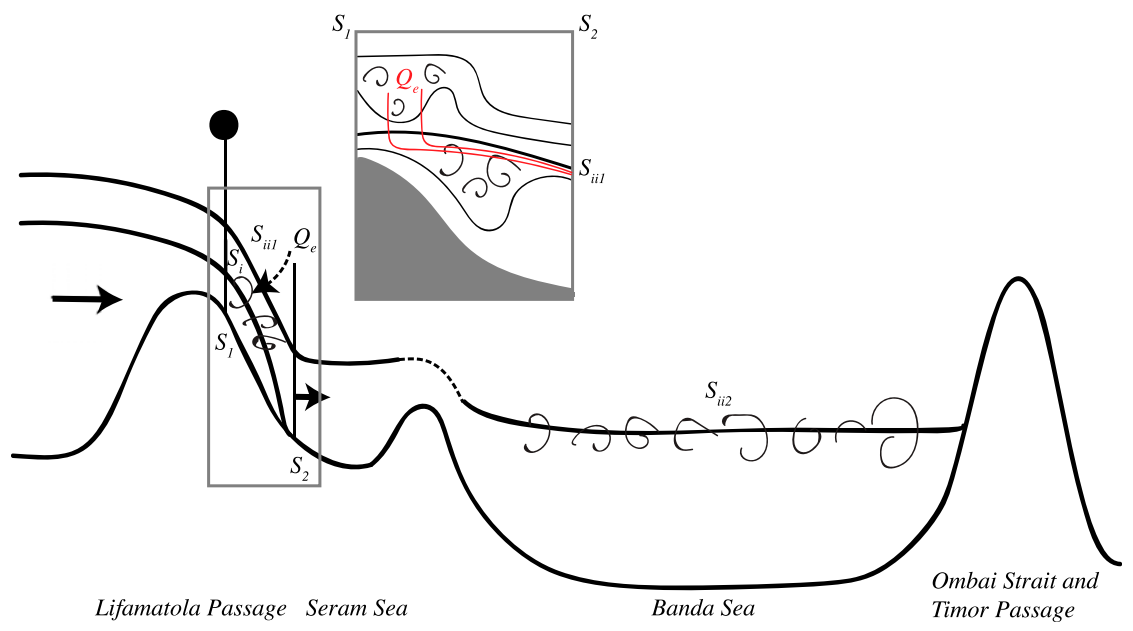

FIG. C1. Schematic picture of the hydraulically controlled overflow as it passes the Lifamatola Passage, grows in volume flux due to entrainment, enters the deep Banda Sea, and upwells. $S_{1}$ and $S_{2}$ represent the vertical cross sections at the mooring station and downstream. $S_{i}$ represents a constant Conservative Temperature interface that grounds downstream. $S_{i i 1}$ is a surface of constant Conservative Temperature spanning $S_{1}$ and $S_{2}$, and $S_{i i 2}$ is the extension of $S_{i i 1}$ in the Banda Sea, where interfacial mixing is expected. The inset is the zoomed-in view of the entrainment region in the gray box. More than one mixed wedge may occur downstream, and the red curves indicate possible streamlines.

of the differences between the unsorted and sorted pseudo buoyancy values divided by the Thorpe scale. A commonly used estimate of the diapycnal diffusivity coefficient is given by (Osborn 1980)

$$
K=\Gamma \varepsilon N^{-2},
$$

in which the mixing coefficient $\Gamma$ is taken as the conventional value of 0.2 (Gregg et al. 2018).

\section{APPENDIX C}

\section{Thermodynamics Formulation in Terms of Potential Enthalpy}

The mass conservation equation and thermodynamic equation with respect to the potential enthalpy $h^{\circ}$ may be written as

$$
\begin{aligned}
\frac{\partial \rho}{\partial t}+\nabla \cdot(\rho v) & =0 \\
\frac{\partial\left(\rho h^{\circ}\right)}{\partial t}+\nabla \cdot\left(\rho v h^{\circ}-\rho K \nabla h^{\circ}\right) & =\rho \varepsilon .
\end{aligned}
$$

For steady state conditions, (C2) specifies that the net advective fluxes into the control volume is balanced by a (usually negligible) sink due to dissipation within the control volume, and by the diffusive fluxes out of the control volume. Combining this budget with the mass budget and applying the result to various control volumes (Fig. C1) allows us to approximate properties like diffusivity and entrainment. Typically, the control volume is delimited by the upstream flow entrance and downstream exit, and by the bottom and an overlying constant Conservative Temperature surface. Under this definition of control volume, the diffusive flux due to the gradient of $h^{\circ}$ that is tangential to a conservative surface is zero. In the below calculations, we will refer to $K$ in (C1) and (C2) as "diapycnal diffusivity coefficient" since density is mostly controlled by temperature in the study region.

\section{a. Diapycnal diffusivity in the Lifamatola Passage overflow}

Here we define a control volume bounded upstream by the cross section at the mooring station $\left(S_{1}\right)$ and a constant Conservative Temperature surface $\left(S_{i}\right)$, $h^{\circ}=h_{i}^{\circ}$, which grounds just downstream of the region of most intense mixing. Subtracting the volume integral of (C2) from the product of $h_{i}^{\circ}$ and integral of (C1), we obtain a bulk estimate of the diapycnal diffusivity coefficient:

$$
K_{(i)}=\frac{h_{i}^{\circ} \iint_{\left(S_{1}\right)} \rho v d S-\iint_{\left(S_{1}\right)} h^{\circ} \rho v d S-\iiint \rho \varepsilon d V}{\left.\rho_{i} \frac{\partial h^{\circ}}{\partial z}\right|_{(i)} S_{i}}
$$


where $S_{1}$ and $S_{i}$ also represent the surface areas.

\section{b. Entrainment estimate at the Lifamatola Passage}

Here the control volume is bounded by the cross section at the mooring station $\left(S_{1}\right)$, a vertical cross section $\left(S_{2}\right)$ located downstream of $\left(S_{1}\right)$, and an upper interface $\left(S_{i i 1}\right)$ with constant Conservative Temperature. The approximation of the potential enthalpy at $\left(S_{2}\right)$ is represented by the depth average value $\overline{h_{2}^{\circ}}$ (i.e., $\iint_{\left(S_{2}\right)} h^{\circ} \rho v d S=$ $\left.\overline{h_{2}^{\circ}} \iint_{\left(S_{2}\right)} \rho v d S\right)$. Without knowing the downstream velocities, this procedure eliminates the advection term at the downstream section $\left(S_{2}\right)$ by subtracting the volume integral of (C2) from the product of $\overline{h_{2}^{\circ}}$ and integral of $(\mathrm{C} 1)$. The volume flux corresponding to cross interface entrainment is given by

$$
Q_{e}=\frac{\overline{h_{2}^{\circ}} \iint_{\left(S_{1}\right)} \rho v d S-\iint_{\left(S_{1}\right)} h^{\circ} \rho v d S-\left.\rho_{i i 1} K_{(i i 1)} \frac{\partial h^{\circ}}{\partial z}\right|_{(i i 1)} S_{i i 1}-\iiint \rho \varepsilon d V}{\left(h_{i i 1}^{\circ}-\overline{h_{2}^{\circ}}\right) \rho_{i i 1}} .
$$

\section{c. Diapycnal diffusivity in the Banda Sea}

The control volume is bounded by section $\left(S_{2}\right)$ and the extension $\left(S_{i i 2}\right)$ of $\left(S_{i i 1}\right)$ into the Banda Sea, where it grounds. The upwelling velocity at $\left(S_{i i 2}\right)$ can be obtained by integrating $(\mathrm{C} 1)$ over this control volume:

$$
w_{(i i 2)}=\frac{\iint_{\left(S_{1}\right)} \rho v d S+\rho_{i i 1} Q_{e}}{\rho_{i i 2} S_{i i 2}} .
$$

The diapycnal diffusivity coefficient at $\left(S_{i i 2}\right)$ can be obtained by subtracting the volume integral of (C2) from the product of $h_{i}^{\circ}$ and integral of (C1):

$K_{(i i 2)}=\frac{h_{i i 2}^{\circ} \iint_{\left(S_{2}\right)} \rho v d S-\iint_{\left(S_{2}\right)} h^{\circ} \rho v d S-\iiint_{\rho} \rho d V}{\left.\rho_{i i 2} \frac{\partial h^{\circ}}{\partial z}\right|_{(i i 2)} S_{i i 2}}$.

The advective fluxes at section $\left(S_{2}\right)$ in (C6) can be eliminated by integrating $(\mathrm{C} 1)$ and $(\mathrm{C} 2)$ over another control volume bounded by $\left(S_{1}\right),\left(S_{2}\right)$, and $\left(S_{i i 1}\right)$ while assuming $\iint_{\left(S_{2}\right)} h^{\circ} \rho v d S=\overline{h_{2}^{\circ}} \iint_{\left(S_{2}\right)} \rho v d S$. These procedures arrive at

$$
K_{(i i 2)}=\frac{h_{i i 2}^{\circ} \iint_{\left(S_{1}\right)} \rho v d S-\iint_{\left(S_{1}\right)} h^{\circ} \rho v d S+\left(h_{i i 2}^{\circ}-h_{i i 1}^{\circ}\right) \rho_{i i 1} Q_{e}-\left.\rho_{i i 1} K_{(i i 1)} \frac{\partial h^{\circ}}{\partial z}\right|_{(i i 1)} S_{i i 1}-\iiint \rho \varepsilon d V}{\left.\rho_{i i 2} \frac{\partial h^{\circ}}{\partial z}\right|_{(i i 2)} S_{i i 2}} .
$$

The potential enthalpy flux over the interface $\left(S_{i i 2}\right)$ is

$$
H_{(i i 2)}=\left.K_{(i i 2)} \rho_{i i 2} \frac{\partial h^{\circ}}{\partial z}\right|_{(i i 2)} .
$$

Since the potential enthalpy is a measure of heat, (C8) also represents the turbulent heat flux, with positive $H$ implying downward turbulent heat fluxes.

\section{REFERENCES}

Alford, M. H., M. C. Gregg, and M. Ilyas, 1999: Diapycnal mixing in the Banda Sea: Results of the first microstructure measurements in the Indonesian throughflow. Geophys. Res. Lett., 26, 2741-2744, https://doi.org/10.1029/1999GL002337.

_ , J. M. Klymak, and G. S. Carter, 2014: Breaking internal lee waves at Kaena Ridge, Hawaii. Geophys. Res. Lett., 41, 906912, https://doi.org/10.1002/2013GL059070.

Amante, C., and B. W. Eakins, 2009: ETOPO1 1 arc-minute global relief model: Procedures, data sources, and analysis. NOAA Tech.
Memo. NESDIS NGDC-24, 25 pp., https:/www.ngdc.noaa.gov/ $\mathrm{mgg} / \mathrm{global} / \mathrm{relief} / \mathrm{ETOPO} 1 / \mathrm{docs} / \mathrm{ETOPO} 1 . \mathrm{pdf}$.

Baines, P. G., 1977: Upstream influence and Long's model in stratified flows. J. Fluid Mech., 82, 147-159, https://doi.org/ 10.1017/S0022112077000573.

- 1995: Topographic Effects in Stratified Flows. Cambridge University Press, $482 \mathrm{pp}$.

Bevington, P. R., and D. K. Robinson, 1992: Data Reduction and Error Analysis for the Physical Sciences. McGraw-Hill, $328 \mathrm{pp}$.

Bryden, H. L., and A. J. G. Nurser, 2003: Effects of strait mixing on ocean stratification. J. Phys. Oceanogr., 33, 1870-1872, https:// doi.org/10.1175/1520-0485(2003)033<1870:EOSMOO>2.0.CO;2.

Chow, V. T., 1959: Open-channel Hydraulics. McGraw-Hill, 680 pp.

Cusack, J. M., G. Voet, M. H. Alford, J. B. Girton, G. S. Carter, L. J. Pratt, K. A. Pearson-Potts, and S. Tan, 2019: Persistent turbulence in the Samoan Passage. J. Phys. Oceanogr., 49, 3179-3197, https://doi.org/10.1175/JPO-D-19-0116.1.

Dillon, T. M., 1982: Vertical overturns: A comparison of Thorpe and Ozmidov length scales. J. Geophys. Res., 87, 9601-9613, https://doi.org/10.1029/JC087iC12p09601.

Drazin, P. G., and W. H. Reid, 1981: Hydrodynamic Instability. Cambridge University Press, 527 pp. 
Farmer, D., and L. Armi, 1999: Stratified flow over topography: The role of small-scale entrainment and mixing in flow establishment. Proc. Roy. Soc. London, 455A, 3221-3258, https://doi.org/10.1098/rspa.1999.0448.

Ffield, A., and A. L. Gordon, 1992: Vertical mixing in the Indonesian thermocline. J. Phys. Oceanogr., 22, 184-195, https://doi.org/ 10.1175/1520-0485(1992)022<0184:VMITIT >2.0.CO;2.

— Seas. J. Phys. Oceanogr., 26, 1924-1937, https:/doi.org/10.1175/ 1520-0485(1996)026<1924:TMSITI >2.0.CO;2.

Gerdes, F., C. Garrett, and D. Farmer, 2002: On internal hydraulics with entrainment. J. Phys. Oceanogr., 32, 1106-1111, https:// doi.org/10.1175/1520-0485(2002)032<1106:OIHWE >2.0.CO;2.

Gill, A. E., 1977: The hydraulics of rotating channel flow. J. Fluid Mech., 80, 641-671, https://doi.org/10.1017/S0022112077002407.

Girton, J. B., and T. B. Sanford, 2003: Descent and modification of the overflow plume in the Denmark Strait. J. Phys. Oceanogr., 33, 1351-1364, https://doi.org/10.1175/1520-0485(2003)033<1351: DAMOTO $>2.0 . \mathrm{CO} ; 2$.

- L. J. Pratt, D. A. Sutherland, and J. F. Price, 2006: Is the Faroe Bank Channel overflow hydraulically controlled? J. Phys. Oceanogr., 36, 2340-2349, https://doi.org/10.1175/JPO2969.1.

Gordon, A. L., 2005: Oceanography of the Indonesian seas and their throughflow. Oceanography, 18, 14-27, https://doi.org/ 10.5670/oceanog.2005.01.

— , R. D. Susanto, and A. Ffield, 1999: Throughflow within Makassar Strait. Geophys. Res. Lett., 26, 3325-3328, https:// doi.org/10.1029/1999GL002340.

__ _ _ , and K. Vranes, 2003a: Cool Indonesian throughflow as a consequence of restricted surface layer flow. Nature, $\mathbf{4 2 5}$, 824-828, https://doi.org/10.1038/nature02038.

— C. F. Giulivi, and A. G. Ilahude, 2003b: Deep topographic barriers within the Indonesian seas. Deep-Sea Res. II, 50, 2205-2228, https://doi.org/10.1016/S0967-0645(03)00053-5.

- - and Coauthors, 2010: The Indonesian throughflow during 2004-2006 as observed by the INSTANT program. Dyn. Atmos. Oceans, 50,115-128, https://doi.org/10.1016/ j.dynatmoce.2009.12.002.

Gregg, M. C., E. A. D'Asaro, J. J. Riley, and E. Kunze, 2018: Mixing efficiency in the ocean. Annu. Rev. Mar. Sci., 10, 443 473, https://doi.org/10.1146/annurev-marine-121916-063643.

Hatayama, T., 2004: Transformation of the Indonesian throughflow water by vertical mixing and its relation to tidally generated internal waves. J. Oceanogr., 60, 569-585, https://doi.org/ 10.1023/B:JOCE.0000038350.32155.cb.

Hautala, S., J. L. Reid, and N. A. Bray, 1996: The distribution and mixing of Pacific water masses in the Indonesian Seas. J. Geophys. Res., 101, 12375-12389, https://doi.org/10.1029/ 96JC00037.

Hogg, A. McC., K. B. Winters, and G. N. Ivey, 2001: Linear internal waves and the control of stratified exchange flows. J. Fluid Mech., 447, 357-375, https://doi.org/10.1017/S0022112001006048.

Hogg, N., P. Biscaye, W. Gardner, and W. J. Schmitz, 1982: On the transport and modification of Antarctic bottom water in the Vema Channel. J. Mar. Res., 40, 231-263.

Hoskins, B. J., 1974: The role of potential vorticity in symmetric stability and instability. Quart. J. Roy. Meteor. Soc., 100, 480482, https://doi.org/10.1002/qj.49710042520.

Howard, L. N., 1961: Note on a paper of John W. Miles. J. Fluid Mech., 10, 509-512, https://doi.org/10.1017/S0022112061000317.

Ijichi, T., and T. Hibiya, 2018: Observed variations in turbulent mixing efficiency in the deep ocean. J. Phys. Oceanogr., 48, 1815-1830, https://doi.org/10.1175/JPO-D-17-0275.1.
Koch-Larrouy, A., G. Madec, P. Bouruet-Aubertot, T. Gerkema, L. Bessières, and R. Molcard, 2007: On the transformation of Pacific water into Indonesian Throughflow Water by internal tidal mixing. Geophys. Res. Lett., 34, L04604, https://doi.org/ 10.1029/2006GL028405.

- , A. Atmadipoera, P. van Beek, G. Madec, J. Aucan, F. Lyard, J. Grelet, and M. Souhaut, 2015: Estimates of tidal mixing in the Indonesian archipelago from multidisciplinary INDOMIX in-situ data. Deep-Sea Res. I, 106, 136-153, https://doi.org/ 10.1016/j.dsr.2015.09.007.

Li, X., and Coauthors, 2020: Moored observations of transport and variability of Halmahera Sea currents. J. Phys. Oceanogr., 50, 471-488, https://doi.org/10.1175/JPO-D-19-0109.1.

Mater, B. D., S. K. Venayagamoorthy, L. St. Laurent, and J. N. Moum, 2015: Biases in Thorpe-scale estimates of turbulence dissipation. Part I: Assessments from large-scale overturns in oceanographic data. J. Phys. Oceanogr., 45, 2497-2521, https:// doi.org/10.1175/JPO-D-14-0128.1.

McDougall, T. J., 2003: Potential enthalpy: A conservative oceanic variable for evaluating heat content and heat fluxes. J. Phys. Oceanogr., 33, 945-963, https://doi.org/10.1175/ 1520-0485(2003)033<0945:PEACOV>2.0.CO;2.

- and P. M. Barker, 2011: Getting started with TEOS-10 and the Gibbs Seawater (GSW) oceanographic toolbox. SCOR/ IAPSO WG127, 28 pp., http://www.teos-10.org/pubs/Getting Started.pdf.

Miles, J. W., 1961: On the stability of heterogeneous shear flows. J. Fluid Mech., 10, 496-508, https://doi.org/10.1017/ S0022112061000305.

Munk, W. H., 1966: Abyssal recipes. Deep-Sea Res. Oceanogr. Abstr., 13, 707-730, https://doi.org/10.1016/0011-7471(66)90602-4.

Nagai, T., T. Hibiya, and P. Bouruet-Aubertot, 2017: Nonhydrostatic simulations of tide-induced mixing in the Halmahera Sea: A possible role in the transformation of the Indonesian Throughflow Waters. J. Geophys. Res. Oceans, 122, 89338943, https://doi.org/10.1002/2017JC013381.

Nielsen, M. H., L. Pratt, and K. Helfrich, 2004: Mixing and entrainment in hydraulically driven stratified sill flows. J. Fluid Mech., 515, 415-443, https://doi.org/10.1017/S0022112004000576.

Osborn, T. R., 1980: Estimates of the local rate of vertical diffusion from dissipation measurements. J. Phys. Oceanogr., 10, 83-89, https:// doi.org/10.1175/1520-0485(1980)010<0083:EOTLRO > 2.0.CO;2.

Ozmidov, R. V., 1965: On the turbulent exchange in a stably stratified ocean. Izv. Acad. Sci. USSR, Atmos. Oceanic Phys., 1, 861-871.

Pandey, V. K., V. Bhatt, A. C. Pandey, and I. M. L. Das, 2007: Impact of Indonesian throughflow blockage on the Southern Indian Ocean. Curr. Sci., 93, 399-406.

Pawlak, G., and L. Armi, 1997: Hydraulics of two-layer arrested wedge flows. J. Hydraul. Res., 35, 603-618, https://doi.org/ 10.1080/00221689709498397.

Pawlowicz, R., B. Beardsley, and S. Lentz, 2002: Classical tidal harmonic analysis including error estimates in MATLAB using T_TIDE. Comput. Geosci., 28, 929-937, https://doi.org/ 10.1016/S0098-3004(02)00013-4.

Peltier, W. R., and T. L. Clark, 1979: The evolution and stability of finite-amplitude mountain waves. Part II. Surface wave drag and severe downslope windstorms. J. Atmos. Sci., 36, 1498-1529, https://doi.org/10.1175/1520-0469(1979) 036<1498:TEASOF $>2.0$. CO;2.

Pratt, L. J., 1986: Hydraulic control of sill flow with bottom friction. J. Phys. Oceanogr., 16, 1970-1980, https://doi.org/10.1175/ 1520-0485(1986)016<1970:HCOSFW >2.0.CO;2. 
, and J. A. Whitehead, 2008: Rotating Hydraulics: Nonlinear Topographic Effects in the Ocean and Atmosphere. Springer, 592 pp.

, H. E. Deese, S. P. Murray, and W. Johns, 2000: Continuous dynamical modes in straits having arbitrary cross sections, with applications to the Bab al Mandab. J. Phys. Oceanogr., 30, 2515-2534, https://doi.org/10.1175/1520-0485(2000)030<2515: $\mathrm{CDMISH}>2.0 . \mathrm{CO} ; 2$.

Schneider, N., 1998: The Indonesian throughflow and the global climate system. J. Climate, 11, 676-689, https://doi.org/10.1175/ 1520-0442(1998)011<0676:TITATG > 2.0.CO;2.

Scorer, R. S., 1949: Theory of waves in the lee of mountains. Quart. J. Roy. Meteor. Soc., 75, 41-56, https://doi.org/10.1002/ qj. 49707532308.

Siddall, M., L. J. Pratt, K. R. Helfrich, and L. Giosan, 2004: Testing the physical oceanographic implications of the suggested sudden Black Sea infill 8400 years ago. Paleoceanography, 19, PA1024, https://doi.org/10.1029/2003PA000903.

Smith, R. B., and J. Sun, 1987: Generalized hydraulic solutions pertaining to severe downslope winds. J. Atmos. Sci., 44, 2934-2939, https://doi.org/10.1175/1520-0469(1987)044<2934: GHSPTS $>2.0 . \mathrm{CO} ; 2$.

Smyth, W. D., J. N. Moum, and D. R. Caldwell, 2001: The efficiency of mixing in turbulent patches: Inferences from direct simulations and microstructure observations. J. Phys. Oceanogr., 31, 1969-1992, https://doi.org/10.1175/1520-0485(2001)031<1969: TEOMIT $>2.0 . \mathrm{CO} ; 2$.

— — _ - and J. D. Nash, 2011: Narrowband oscillations in the upper equatorial ocean. Part II: Properties of shear instabilities. J. Phys. Oceanogr., 41, 412-428, https://doi.org/10.1175/ 2010JPO4451.1.

St. Laurent, L., and R. W. Schmitt, 1999: The contribution of salt fingers to vertical mixing in the North Atlantic Tracer Release Experiment. J. Phys. Oceanogr., 29, 1404-1424, https://doi.org/10.1175/1520-0485(1999)029<1404:TCOSFT> 2.0.CO;2.

— J. M. Toole, and R. W. Schmitt, 2001: Buoyancy forcing by turbulence above rough topography in the abyssal Brazil basin. J. Phys. Oceanogr., 31, 3476-3495, https://doi.org/ 10.1175/1520-0485(2001)031<3476:BFBTAR > 2.0.CO;2.

Talley, L. D., and J. Sprintall, 2005: Deep expression of the Indonesian Throughflow: Indonesian intermediate water in the South Equatorial Current. J. Geophys. Res., 110, C10009, https://doi.org/10.1029/2004JC002826.

Tessler, Z. D., A. L. Gordon, L. J. Pratt, and J. Sprintall, 2010: Transport and dynamics of the Panay Sill overflow in the Philippine Seas. J. Phys. Oceanogr., 40, 2679-2695, https:// doi.org/10.1175/2010JPO4395.1.

Thomas, L. N., J. R. Taylor, R. Ferrari, and T. M. Joyce, 2013: Symmetric instability in the Gulf Stream. Deep-Sea Res. II, 91, 96-110, https://doi.org/10.1016/j.dsr2.2013.02.025.

Thorpe, S., 1977: Turbulence and mixing in a Scottish loch. Philos. Trans. Roy. Soc. London, 286A, 125-181, https://doi.org/ 10.1098/rsta.1977.0112.

van Aken, H. M., J. Punjanan, and S. Saimima, 1988: Physical aspects of the flushing of the East Indonesian basins. Neth. J. Sea Res., 22, 315-339, https://doi.org/10.1016/0077-7579(88)90003-8.

_ I. S. Brodjonegoro, and I. Jaya, 2009: The deep-water motion through the Lifamatola passage and its contribution to the Indonesian throughflow. Deep-Sea Res. I, 56, 1203-1216, https://doi.org/10.1016/j.dsr.2009.02.001.

Wagner, G. L., G. Flierl, R. Ferrari, G. Voet, G. S. Carter, M. H. Alford, and J. B. Girton, 2019: Squeeze dispersion and the effective diapycnal diffusivity of oceanic tracers. Geophys. Res. Lett., 46, 5378-5386, https://doi.org/10.1029/2019GL082458.

Wajsowicz, R. C., and E. K. Schneider, 2001: The Indonesian Throughflow's effect on global climate determined from the COLA coupled climate system. J. Climate, 14, 3029-3042, https:// doi.org/10.1175/1520-0442(2001)014<3029:TITSEO>2.0.CO;2.

Whitehead, J. A., and L. V. Worthington, 1982: The flux and mixing rates of Antarctic bottom water within the North Atlantic. J. Geophys. Res., 87, 7903-7924, https://doi.org/10.1029/ JC087iC10p07903.

Wyrtki, K., 1961: Physical oceanography of the southeast Asian Waters. NAGA Rep. 2, Scripps Institution of Oceanography, $226 \mathrm{pp}$.

Yuan, D., and Coauthors, 2011: Forcing of the Indian ocean dipole on the interannual variations of the tropical pacific ocean: Roles of the Indonesian Throughflow. J. Climate, 24, 35933608, https://doi.org/10.1175/2011JCLI3649.1.

- H. Zhou, and X. Zhao, 2013: Interannual climate variability over the tropical Pacific Ocean induced by the Indian Ocean dipole through the Indonesian Throughflow. J. Climate, 26, 2845-2861, https://doi.org/10.1175/JCLI-D-12-00117.1. 